\title{
CFD modelling of axial mixing in the intermediate and final rinses of cleaning-in-place
} procedures of straight pipes

Yang, Jifeng; Jensen, Bo Boye Busk; Nordkvist, Mikkel; Rasmussen, Peter; Gernaey, Krist V.; Krühne, Ulrich

Published in:

Journal of Food Engineering

Link to article, DOI:

10.1016/j.jfoodeng.2017.09.017

Publication date:

2018

Document Version

Peer reviewed version

Link back to DTU Orbit

Citation (APA):

Yang, J., Jensen, B. B. B., Nordkvist, M., Rasmussen, P., Gernaey, K. V., \& Krühne, U. (2018). CFD modelling of axial mixing in the intermediate and final rinses of cleaning-in-place procedures of straight pipes. Journal of Food Engineering, 221, 95-105. https://doi.org/10.1016/j.jfoodeng.2017.09.017

\section{General rights}

Copyright and moral rights for the publications made accessible in the public portal are retained by the authors and/or other copyright owners and it is a condition of accessing publications that users recognise and abide by the legal requirements associated with these rights.

- Users may download and print one copy of any publication from the public portal for the purpose of private study or research.

- You may not further distribute the material or use it for any profit-making activity or commercial gain

- You may freely distribute the URL identifying the publication in the public portal 


\section{Accepted Manuscript}

CFD modelling of axial mixing in the intermediate and final rinses of cleaning-in-place procedures of straight pipes

Jifeng Yang, Bo Boye Busk Jensen, Mikkel Nordkvist, Peter Rasmussen, Krist V.

Gernaey, Ulrich Krühne

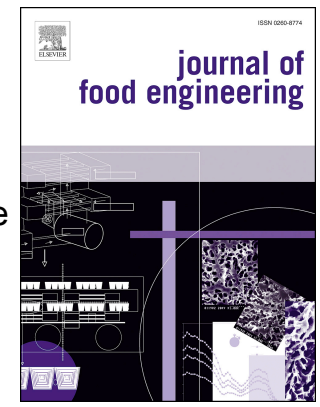

PII:

S0260-8774(17)30407-7

DOI:

10.1016/j.jfoodeng.2017.09.017

Reference: JFOE 9021

To appear in: Journal of Food Engineering

Received Date: 7 December 2016

Revised Date: 18 August 2017

Accepted Date: 22 September 2017

Please cite this article as: Yang, J., Jensen, B.B.B., Nordkvist, M., Rasmussen, P., Gernaey, K.V., Krühne, U., CFD modelling of axial mixing in the intermediate and final rinses of cleaning-in-place procedures of straight pipes, Journal of Food Engineering (2017), doi: 10.1016/j.jfoodeng.2017.09.017.

This is a PDF file of an unedited manuscript that has been accepted for publication. As a service to our customers we are providing this early version of the manuscript. The manuscript will undergo copyediting, typesetting, and review of the resulting proof before it is published in its final form. Please note that during the production process errors may be discovered which could affect the content, and all legal disclaimers that apply to the journal pertain. 


\section{CFD modelling of axial mixing in the intermediate and final rinses of}

Cleaning-in-Place procedures of straight pipes

Jifeng Yang ${ }^{1}$, Bo Boye Busk Jensen ${ }^{2}$, Mikkel Nordkvist ${ }^{2}$, Peter Rasmussen ${ }^{3}$, Krist V Gernaey ${ }^{1}$, Ulrich Krühne ${ }^{1 *}$

${ }^{1}$ Process and Systems Engineering Center (PROSYS), Department of Chemical and Biochemical Engineering, Technical University of Denmark, 2800 Kgs. Lyngby, Denmark

${ }^{2}$ Alfa Laval Copenhagen A/S, 2860 Søborg, Denmark

${ }^{3}$ Carlsberg Danmark A/S, 7000 Fredericia, Denmark

${ }^{*}$ Correspondence to Ulrich Krühne, E-mail: ulkr@kt.dtu.dk, Tel: +45 45252960

Abstract:

The intermediate and final rinses of straight pipes, in which water replaces a cleaning agent of similar density and viscosity, are modelled using Computational Fluid Dynamic (CFD) methods. It is anticipated that the displacement process is achieved by convective and diffusive transport. The simulated agent concentrations show good agreement with the analytical axial mixing models from

14 literature. The displacement time, minimum water consumption, minimum generation of wastewater and minimum requirement of intermediate rinsing water are evaluated using CFD. Practical empirical equations are derived from CFD results and applied to examine if the process is operated in an efficient and economic manner. It has been found that the displacement time can be predicted from the inner pipe diameter and the mean flow velocity using a power law relationship. Changing flow velocities does not significantly influence the minimum water consumption and the minimum wastewater generation for rinsing a pipe. Controlling the rinsing step based on a downstream measurement still consumes more water than the minimum requirement to reduce contamination risks. This article presents an innovative algorithm for optimizing the rinse steps with lower water consumption based on the above observations. A case of rinsing a $24 \mathrm{~m}$ long straight pipe describes the promising application of the CFD study. The recovery of cleaning agent can be up to $89.3 \%$ of the 
25 volume and the saving of intermediate rinsing water can be at least $55 \%$ compared to the conventional 26 rinse method. The work in this article presents an example showing how to deal with more complex 27 systems in the future.

28 Keywords: Rinse; CFD; CIP; Axial mixing; Reducing water consumption 


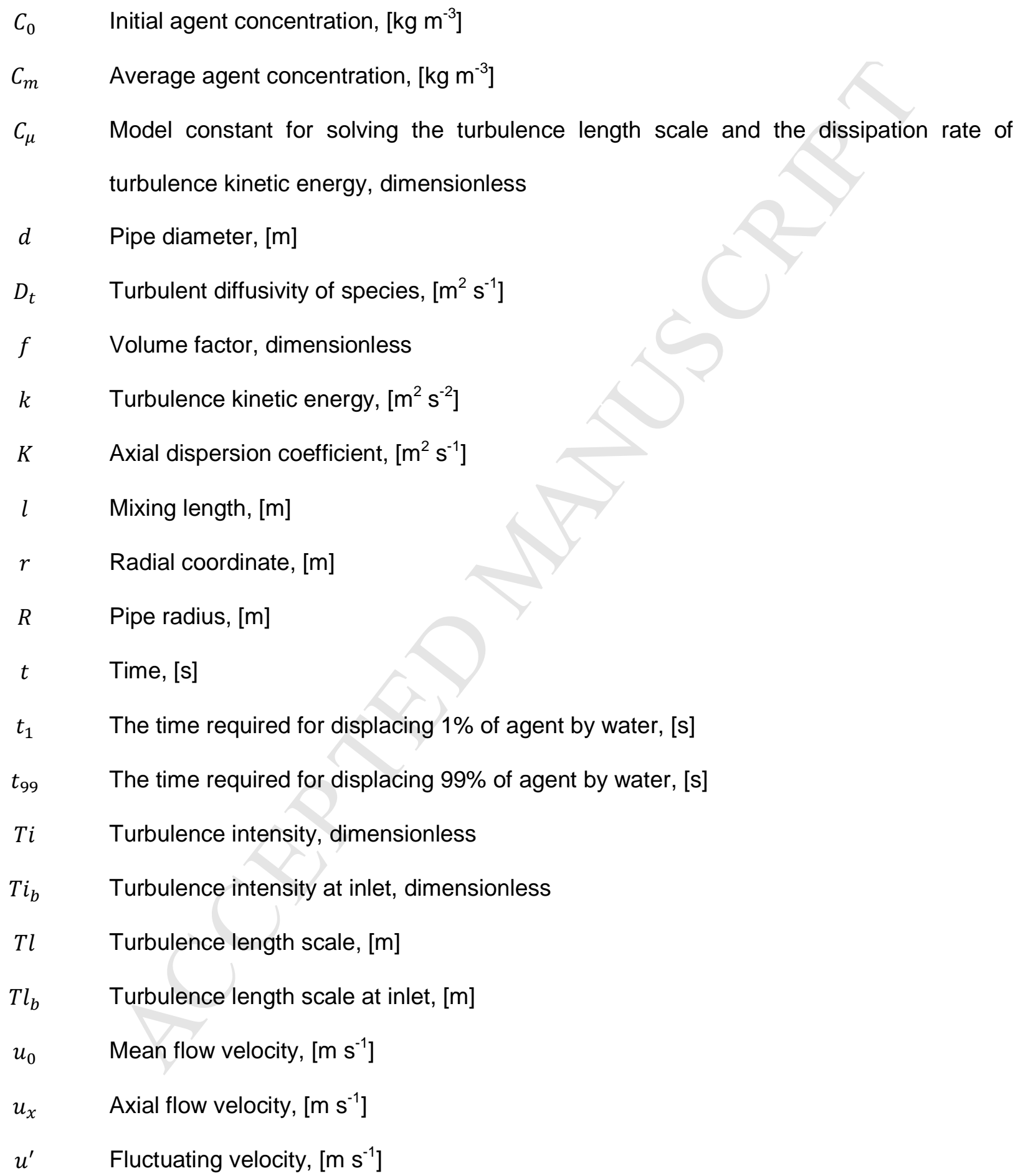




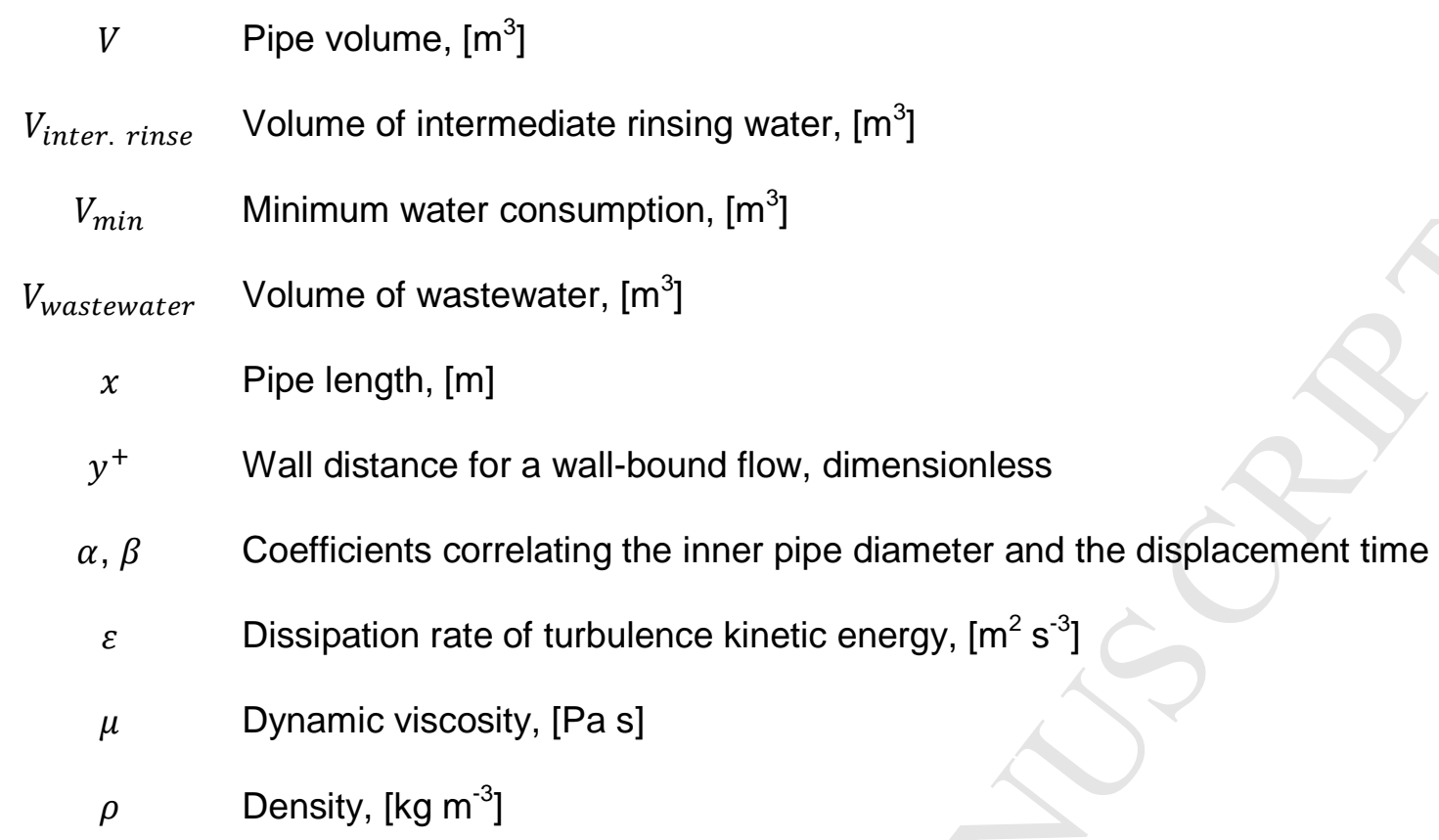

Abbreviations

CFD Computational Fluid Dynamics

CIP Cleaning-in-place

DN Nominal diameter

EHEDG European Hygienic Engineering \& Design Group

ERT Electrical resistance tomography

RTD Residence time distribution 
1. Introduction

34 Cleaning-in-place (CIP) has become a common practice in food processing. The concept of CIP is to clean components of a plant or pipe without dismantling or opening the equipment and with little or no manual involvement of the operator (Lelieveld et al., 2005). In the food industry, CIP tends to consist of a series of similar steps, including: Pre-rinse for removing excessive soils from the system; (3) Circulation of alkaline solution to lift the soils from Intermediate rinse by water for removing the alkaline and entrained soils;

(5) Circulation of acid solution to remove inorganic soils; (6) Intermediate rinse using water for removing acid; (7) Disinfection (optional) to eliminate microorganisms if a sanitary environment is required for the subsequent processes; (8) Final rinse (optional) to remove residual agents. If there is no disinfection step, the water quality in step 6 is often improved by treating with chlorine dioxide (Tamime, 2008).

In a recent mapping project performed at a leading brewery manufacturing site (Carlsberg Denmark), more than 33 CIP operations occur every day for cleaning tanks and pipes. Among these CIPs, pipe cleanings contribute with over $50 \%$ of the costs (Yang, 2017). Figure 1 (A) and (B) display the cleaning time of each step and the costs connected to a typical CIP of transfer pipes, respectively. Most of the cleaning time and costs are spent on alkaline/acid treatment, disinfection and the three rinsing steps (two intermediate rinses and one final rinse). The recovery of the cleaning detergents

51 (alkaline and acid) can be up to $95 \%$ of the supply. In some industries, the final rinsing water can be 52 partly recycled for the pre-rinse of the next CIP. The intermediate rinsing water is rarely recycled.

53 Therefore, the overall recovery efficiency of rinsing water is very low, even less than $10 \%$. Most of the 54 rinsing water is directly disposed to drain. 
55 Cleaning generates large amounts of wastewater containing corrosive pollutants, nutrients, and 56 potentially a considerable organic load. Furthermore, heat losses due to discharge of hot water also 57 contribute to the overall costs. Minimizing the environmental impact of cleaning has become more and more important due to the legislative pressures towards establishing zero emission processes

59 (Palabiyik. 2013). A number of studies have focused on the development of new cleaning agents, the 60 effect of water quality and the optimization of chemical usage (Chen et al., 2012; Jurado-Alameda et 61 al., 2016; Palabiyik et al., 2015). However, industrial applications of such technologies are still limited due to the complex modification of existing equipment and the inestimable payback time. Operators

63 tend to prefer simple changes in operation without significant transformation of the existing processes.

64 Therefore, reducing the water consumption by optimizing flow rates and rinsing time in rinsing steps and improving the recovery efficiency of cleaning agent becomes a practical solution for many food industries, as the operators can easily change and dynamically adapt the flows at the control panel.

67 The rinsing objective is to displace residual cleaning agents (alkaline, acid and disinfectant) and reduce cross-contamination risks (Tamime, 2008). Such displacement of one liquid (chemical agent) with another liquid (water) occurs at the interface of two liquids, where an axial mixing zone is created due to convection and diffusion phenomena (Wiklund et al., 2010). The knowledge about axial mixing and the displacement zone is of importance in order to ensure complete chemical removal at reduced water consumption.

73 Computational fluid dynamics (CFD) methods are powerful in order to understand and predict fluid

74 flows. A number of studies have applied CFD methods to understand how the local hydrodynamic 75 conditions, e.g. shear stress and fluctuation intensity, affect cleaning results (Jensen et al., 2006; 76 Jensen and Friis, 2005; Schöler et al., 2012) and to improve the hygienic design of valves, pipes and 77 connections (Friis and Jensen, 2002; Jensen and Friis, 2004). Li et al. (2015a, 2015b) simulated a 78 four-lobed swirl pipe by using CFD and identified the potential to improve the efficiency of CIP by 
79 introducing swirl impact by increasing the local wall shear stress. CFD could also successfully predict

80 the displacement of yoghurt by water, which agreed well with the measurement by using electrical

81 resistance tomography (ERT) electrode planes (Henningsson et al., 2007).

82 Nearly all CFD studies applied to CIP considered water as the fluid to remove soils from the surfaces.

83 There are, to our knowledge, no CFD investigations about the intermediate or final rinses where water

84 is mainly used to displace cleaning agents. Compared with analytical mathematical models, the use of

85 CFD models can get the information about mixing in both axial and radial directions. In some cases,

86 CFD models can replace on-line measurement, as the installation of probes increases the capital cost

87 and may introduce new areas that are difficult to clean. Moreover, CFD applies to complex geometries

88 and is very helpful in the frame of hygienic design.

89 Pipe systems embrace several types of elements, e.g. straight pipes, bends, T-joints, expansions, 90 contractions and valves. The cleaning difficulties vary depending on the design of these elements and 91 the operation conditions. Investigating single and simple geometries is an important step if the 92 complex geometries with various pipe elements are going to be studied. Therefore, the purpose of this 93 paper is to simulate the axial mixing and the displacement phenomenon in the intermediate and final 94 rinses of CIP procedures for straight pipes using CFD. The CFD results are validated using published 95 empirical results based on an analytical mixing model for a turbulent flow regime in order to gain 96 confidence in CFD for future studies of more complex systems. A detailed understanding of the axial 97 mixing in CIP supports the knowledge about the effects of flow patterns on the process. The minimal 98 time required to completely displace the residual agents can also be predicted. Furthermore, the total 99 water consumption can be minimized by the proper combination of flow rate and rinsing time as well 100 as by the implementation of efficient recovery plans.

101 2. Methods 
102 This section describes two models: the first is the Taylor model, which provides an analytical solution 103 to describe the axial mixing of two fluids in a pipe; another is the CFD model, which is developed in 104 this study.

$105 \quad$ 2.1. Taylor model

106 The Taylor model (in equation 1) describes the axial dispersion of steady incompressible Newtonian 107 fluids flowing in the laminar regime. The model has then been extended to cover non-Newtonian fluids 108 and turbulent flows (Levenspiel, 1958; Zhao et al., 2010):

$$
C_{m}=\frac{C_{0}}{2}\left(1-\operatorname{erf}\left(\frac{x-u_{0} t}{2 \sqrt{K t}}\right)\right)
$$

109 where $C_{m}$ is the average agent concentration at length $x$ and time $t, C_{0}$ is the initial agent 110 concentration, $u_{0}$ is the mean flow velocity, $K$ is the axial dispersion coefficient, erf is the error 111 function. In the process of water displacing cleaning solutions in a pipe, the boundary conditions are

$$
\begin{aligned}
& \text { when } \mathrm{t}=0, C=\mathrm{C}_{0} \text { at } x \geq 0 \\
& \text { when } \mathrm{t}>0, C=0 \text { at } x=0
\end{aligned}
$$

112 The empirical correlation of the axial dispersion coefficient for turbulent flows based on experimental 113 measurements, $K$, is according to Salmi et al. (2010):

$$
\frac{K}{u_{0} d}=\frac{3 \times 10^{7}}{R e^{2.1}}+\frac{1.35}{R e^{0.125}}
$$

114 where $u_{0}$ is the mean flow velocity, $d$ is the inner pipe diameter, $R e=d u_{0} \rho / \mu$ is the Reynolds number.

115 Under the studied flow conditions, which are described later, the second term on the right hand side in 116 equation 3 dominates the value of $K$. So the dependency of $K$ on $u_{0} d$ can also be approximated by a 117 correlation of $\left(u_{0} d\right)^{7 / 8}$.

118 2.2. CFD simulation 
120 A series of horizontal straight pipes of $28 \mathrm{~m}$ in length were simulated. The inner diameters of the pipes 121 were $15.80,26.64,40.90,77.90$ and $154.10 \mathrm{~mm}$ respectively, in accordance with the European pipe 122 size standards of DN 15, 25, 40, 80 and $150 \mathrm{~mm}$ with the pipe wall thickness defined by the standard pipe schedule. The surface boundaries were modelled as smooth, which is required for food processing.

The geometries were simplified to be quarter sections, as the flow profiles were symmetric along the radial direction. Such a simplification reduced the computational time significantly compared with the simulation of the whole pipe geometry. It also retained cuboid mesh elements at the center of the pipes. Structured hexahedral meshes were made with help of the meshing software ANSYS ICEM CFD 16.2. A mesh independence test was carried out and described in section 2.2.3 (comparing cases 2,6 and 7 ) in order to minimize the errors associated with the mesh size. The mesh layers in the near-wall regions were enhanced to capture the flow details close to the wall (Figure 2). The resulting meshes had a fixed number of nodes in the axial direction (501 nodes) and varying numbers of layer nodes in the radial direction. The attained values of $y^{+}$, the dimensionless distance from the wall, are $27-67$. The total number of mesh elements was $37650,72794,180646,663646$ and 2098360 respectively, contributing to a mesh density of $450-770$ elements $/ \mathrm{mL}$.

\subsubsection{CFD model description}

Water and the agent solutions are miscible. The properties of the agent solution (i.e. density and viscosity) were assumed to be the same as water. Therefore, a single liquid phase simulation was made in this study.

First, a steady state simulation was performed using water to obtain the flow profiles. The inlet was set as plug flow with the mean flow velocities of $1.0,1.5$ and $2.0 \mathrm{~m} / \mathrm{s}$, corresponding to the standard 
142 working velocity range in industrial practices (Chisti and Moo-Young, 1994). The outlet was defined 143 with a relative pressure of $0 \mathrm{~Pa}$. The Reynolds numbers were calculated to be above 17000 . Thus, all 144 the flows were fully turbulent. The effects of turbulence intensity $(T i)$ and turbulence length scale ( $T l)$ 145 at the inlet boundary are presented in section 2.2.3 (comparing cases 1 - 5).

146 Subsequently, a transient simulation was performed using the steady results as initial conditions. The 147 pipe was divided into two sections in order to eliminate the entrance effects under which the flow was 148 not fully developed. It was crucial to introduce this additional length of the pipe, since a boundary 149 condition at the inlet was chosen, where at any point of the inlet the same velocity was defined. 150 Therefore, a certain length was needed, before the correct velocities in radial direction were 151 established as shown in Figure 3. The first section was $-3 \leq x<0 m$, where water was flushed from $152 t=0$ and contacted with the agent solution at $x \geq 0 \mathrm{~m}$. The second section was $0 \leq x \leq 25 \mathrm{~m}$, where 153 the cleaning agent components were dissolved in water with an initial concentration of $1 \mathrm{~kg} / \mathrm{m}^{3}$. The 154 agent component was expressed as an additional volumetric variable, which could be transported 155 through the flow via diffusion and convection (ANSYS CFX-Solver Theory Guide, ANSYS INC, 2013).

156 Buoyancy was not taken into account, because it has been tested that buoyancy did not contribute 157 much to axial mixing, especially when there was no density difference between the two fluids (Zhao et 158 al., 2010). The axial dispersion coefficients were determined with help of equation 3. In the studied 159 flow conditions, the $K$ values range from $0.006-0.08 \mathrm{~m}^{2} / \mathrm{s}$ and the second term on the right hand 160 side in equation 3 contributes with over $90 \%$ to calculation of the $K$ value.

161 The model was built with help of ANSYS CFX version 16.2 using the standard $k-\varepsilon$ turbulence model 162 with scalable wall functions. The advection scheme was set to be high resolution. Steady state 163 simulations in the CFX software are pseudo transient simulations, where also a timescale has to be 164 defined. This can be done automatically, which was our approach, or otherwise a time step has to be 
defined (physical timescale). For the here presented steady state simulations, the timescale was automatically controlled by the CFX-Solver software (auto timescale) to $0.032 \mathrm{~s} \sim 0.15 \mathrm{~s}$. The iterations were forced to run for minimum 500 steps, even though the convergence criteria (residual target MAX $\leq 0.00001$ ) had been reached after $\sim 100$ steps. For the transient simulations, the Courant number is of fundamental importance to reflect the part of a mesh element that a solute will traverse by advection in a time step. The definition is the product of the local velocity and the time step, divided by the mesh element characteristic length. In the simulations, the time step was $0.01 \mathrm{~s}$, corresponding to the maximum Courant number of $0.42-0.92$ for different pipe diameters and flow velocities.

\subsubsection{Mesh independence test and inlet boundary conditions}

Table 1 shows 7 cases of simulations which were carried out to minimize the errors associated with the mesh size and flow inlet conditions. The mesh study was performed by refining the mesh in single radial direction (case 7) or in both radial and axial directions (case 6), and comparing the turbulence intensity near the wall and the average agent concentrations at different distances with the reference case 2. All the studies were performed based on the inner pipe diameter of $40.90 \mathrm{~mm}$ (DN 40) and a flow velocity of $1.5 \mathrm{~m} / \mathrm{s}$.

In addition to the flow velocity, the turbulence at the inlet is defined by the turbulence intensity $(T i)$ and the turbulence length scale (Tl) (Wilcox, 2006). In this study, the turbulence magnitude of the inlet was studied by comparing cases $1-5$ in Table 1 , with changing turbulence intensity $(1-20 \%)$ and turbulence length scale $(5-30 \%$ of the pipe diameter). This approach was similar to the study of the influence of turbulence intensity at the inlet on wall shear stress fluctuations by Jensen (2007). Based on the results of the near-wall turbulence intensity in the steady state simulations and the predicted agent concentration at fixed planes in the transient simulations, the selected inlet boundary conditions for the final model were $T i=5 \%$ and $T l=10 \%$ of the pipe diameter. 


\section{Results and discussions}

\subsection{Studies of mesh independence and inlet boundary conditions}

The predicted near-wall turbulence intensity initially drops, then rises, and reaches a uniform constant value ( 0.056) apart from the pipe section covering the first $2 \mathrm{~m}$ after the entrance (as shown in Figure 4). Comparing cases $6 \& 7$ with case 2 , finer meshes in radial and axial directions lead to a larger turbulence intensity in the turbulent section, but the change is less than $1 \%$ of deviation. Therefore, the differences caused by mesh sizes as well as the turbulence intensity and turbulence length scale are only limited to the initial $2 \mathrm{~m}$ pipe section.

Equation 1 indicates that $C_{m}=C_{0} / 2$ at the mid-plane, which is defined as the plane where the front of the water phase arrives when an ideal plug flow is assumed $\left(x=u_{0} t\right)$. Figure 5 illustrates the average agent concentrations at four mid-planes $(1.5 \mathrm{~m}, 9 \mathrm{~m}, 15 \mathrm{~m}$ and $21 \mathrm{~m})$ simulated for the 7 model cases. It is found that all of the predicted values of $C_{m}$ are lower than the theoretical value, which is mostly caused by the discretization error when a fluid domain is subdivided into a mesh. However, all of the deviations are less than $1 \%$ of the theoretical value calculated by equation 1 . In particular, cases $1-5$ result in the same average agent concentration values (with precision $0.00001 \mathrm{~kg} / \mathrm{m}^{3}$ ) at the four midplanes. This observation strengthens the conclusion drawn from Figure 4 that the turbulence intensity and turbulence length scale of the inlet only affect the flow and mixing near the entrance, but no longer at $x=0$.

Hence, if the analysis omits the entrance section, the mesh refinement, as presented for the cases 6 and 7, is not necessary. Case 2 provides a sufficient mesh for this project. Extremely fine meshes may be counterproductive, because the mixing in radial direction is not significant (consider also Figure 9) and flat mesh elements lead to low mesh quality in slender pipes. The results imply that the use of $3 \mathrm{~m}$ pipe as entrance, as illustrated in Figure 3 , is a reasonable measure to overcome the effects of 
211 entrance fluctuations. The meshes of other pipe diameters were made by fixing axial nodes similar to

212 case 2 and adjusting radial nodes to result in identical layer size and $y^{+}$. The inlet boundary conditions

213 are selected to $T i=5 \%$ and $T l=10 \%$ of the pipe diameter. When a new mesh and a new flow

214 velocity were employed, the same validation approaches as demonstrated in Figure 4 and Figure 5 215 were carried out in order to ensure that the flow was in a turbulent condition at $x=0 \mathrm{~m}$ and $C_{m} \approx$ $216 \quad 0.5 C_{0}$ at the mid-planes.

217 3.2. Comparison of the Taylor model with CFD simulations

218 Figure 6 shows the agent concentrations at the mean flow velocity of $1.5 \mathrm{~m} / \mathrm{s}$ at $x=15 \mathrm{~m}$ and for a 219 fixed rinsing time (10 s) at an arbitrary distance. The presented values in Figure 6 are obtained from 220 the calculations by the Taylor model (Taylor, 1953) and the CFD simulations. Figure 6(A) can be 221 regarded as the displacement dynamics at the fixed plane during the rinsing period. Figure 6(B) can 222 be regarded as the agent distributions within the pipe after $10 \mathrm{~s}$ of rinsing.

223 The agent components transfer slower near the wall than in the center due to blunt velocity profiles 224 (Figure 7). The longer tails in larger pipes (Figure 6) indicate that the agent components are axially 225 mixed faster in the pipe center but slower near the wall than in smaller pipes. The mixing of agent 226 molecules is a result of convection and diffusion (Wiklund et al., 2010). According to equation 3, the 227 value of the axial dispersion coefficient increases with increasing pipe diameter when the flow is 228 turbulent (Salmi et al., 2010). In Figure 7, the value of $k$ is minimal at the center and increases towards 229 the radial direction, and decreases near the wall, which is the same as Zhao et al. (2010) observed 230 when simulating the mixing of two miscible liquids with different densities. Considering the velocity of 231 the largest pipe at the center is $\sim 3 \%$ lower than the smallest pipe, it can be concluded that the mixing 232 of the agent component is governed by axial diffusion in the pipe center section, and by convection 233 near the wall. 
234 CFD successfully predicts the values which are calculated with help of the Taylor model (Taylor, 1953). 235 The model therewith predicts accurately the analytical model in terms of the transient agent concentrations at different locations in the pipe. In addition to the Taylor model, the prediction of dispersion within a pipe by using CFD has also been verified to be successful by predicting Sugiharto et al. (2013)'s experimental data and the residence time distribution (RTD) theory (Bailey and Ollis, 1986). The validations of the latter two approaches are provided in supplementary materials. 240 Therefore, the CFD model is used for further investigations of the displacement process and the mixing zone analysis.

\subsection{Displacement time}

Three displacement times are defined in this work for different purposes:

- $t_{1, \text { plane }}$ is the time when $1 \%$ of the agent is displaced by water at a fixed plane $\left(C_{m}=0.99 C_{0}\right)$. It is assumed to be the detected start point of rinsing when measurements are employed to determine the agent concentration. The sensor is located at the flow downstream from where the plane lies;

- $t_{99, p l a n e}$ is the minimum rinsing time to remove $99 \%$ of the agent component at the fixed plane $\left(C_{m}=0.01 C_{0}\right)$. In practice, it is the apparent time where rinsing ends once the downstream measurement outputs reach the pre-defined rinsing criteria;

- $t_{99, \text { volume }}$ is the minimum rinsing time to remove $99 \%$ of the cleaning agent from the volume, which is the true time required to replace the agent component and reduce contamination risks.

253 The selection of $99 \%$ as complete rinsing refers to Graßhoff's (1983) work when studying the 254 displacement of one liquid with another liquid during CIP. Depending on the initial agent concentration 255 and the requirement of cleaning in different industries, the minimum rinsing time may be defined to remove more or less than $99 \%$ of cleaning agent in order to achieve a safe level. 
257 It is observed that the product of the displacement time and the mean flow velocity, $t_{1 \text { or } 99} \cdot u_{0}$, is 258 constant for different flow velocities, which can be correlated by a power function like equation 4 with 259 the inner pipe diameter as variable. Figure 8 illustrates $t_{1 \text { or } 99} \cdot u_{0}$ against the inner pipe diameter at 260 different length of pipe sections. The values of the correlation parameters for three pipe lengths (2, 15 261 and $24 \mathrm{~m}$ ) are presented in Table 2 . The small values of $\beta$ indicate that the rinsing times are mainly 262 influenced by the flow velocity and pipe length, instead of the pipe diameter. In a CIP rinse, such 263 correlations help to make predictions about when the recovery of agent should be stopped and when 264 the recovery of rinsing water should be launched.

$$
t_{1 \text { or } 99} \cdot u_{0}=\alpha \cdot d^{\beta}
$$

265 An increase in pipe diameter not only speeds up the start of displacement, but also prolongs the 266 termination of displacement. It is caused by the longer tailing distribution of agent components in 267 larger pipes as described in Figure 6, which is observed in both CFD and Taylor models. The obtained 268 minimum rinsing time values based on the fixed plane are greater than the values based on the 269 volume. It can be understood in such a way that when $99 \%$ of the cleaning agent is removed from the 270 volume, the volume-weighted average agent concentration is $1 \%$ of the initial concentration. 271 Meanwhile, agent concentrations near the inlet are lower than near the outlet. So the average agent 272 concentration at the outlet plane is still above $1 \%$ at $t_{99, \text { volume. }}$ In practice, the rinsing time can be 273 determined by measuring the agent concentration downstream and rinsing stops exactly when the 274 agent concentration reaches the pre-defined criteria. However, the apparent rinsing time in such a 275 situation is still longer than the true requirement in order to reduce contamination risks.

$276 \quad$ 3.4. Minimum water consumption for rinsing

277 The minimum water consumption for an effective rinsing is the minimum requirement of water to 278 reduce the amount of agent to such a low degree that the residues have no or only a minor effect on 
279 the following steps. In this study, the removal of $99 \%$ of agent components is assumed as a complete 280 rinse. In order to compare the minimum consumption for different pipe diameters, a volume factor, $f$, 281 is defined as the ratio between the minimum water consumption, $V_{\min }$, and the pipe volume, $V$, as 282 follows:

$$
f=\frac{V_{\min }}{V}=\frac{\pi d^{2} / 4 \cdot u_{0} \cdot t_{\min }}{\pi d^{2} / 4 \cdot x}=\frac{u_{0} \cdot t_{99}}{x}
$$

283 Equation 4 indicates that the value of $u_{0} \cdot t_{99}$ only depends on the inner pipe diameter for a given pipe 284 length. Therefore, according to equation 5, the values of volume factors are independent of flow 285 velocities as well. The increase in flow velocity reduces the cleaning time significantly, but it does not 286 affect the minimum water consumption. However, if water also works as a medium to remove soils 287 from surfaces, large flow velocities improve cleaning efficiency by destroying the structure between 288 soils and surfaces by mechanical forces, i.e. shear stress (Tamime, 2008). The pipes of larger size 289 lead to larger volume factors, as $t_{99}$ increases with increasing inner pipe diameters. Both the 290 numerator and denominator in equation 5 increase for longer pipes, but the value of $u_{0} \cdot t_{99}$ grows 291 slower than $x$. Thus, the volume factors become smaller for longer pipes.

292 With decreasing pipe diameter and increasing pipe length, the volume factor values tend to the lower 293 limit of 1, indicating that the minimum water consumption approaches the pipe volume. It can also be 294 concluded that the calculated volume factors based on the downstream measurement are larger than 295 the values based on the volume, which is the same trend as the illustrated cleaning time in Figure 8. 296 Therefore, if the cleaning time is controlled by downstream measurements, the consumption of water 297 is still $6-20 \%$ more than the real demand to remove a certain amount of agent from the volume. 
299 Recovering of cleaning agent and rinsing water is an efficient solution to reduce the cleaning cost. For 300 a given pipe length, the recovery plan can be made in the following way:

- The recovery of cleaning agent stops at $t_{1, p l a n e}$. So the agent solution is still in high concentration without dilution and can be reused with high activity.

- The recovery of rinsing water starts at $t_{99, p l a n e}$, as the rinsing water is less "polluted" by the agent components. The recovered water can be used for the pre-rinse of the next cleaning or for other applications where the water quality fits.

- The effluent between $t_{1, \text { plane }}$ and $t_{99, \text { plane }}$ is a mixture of the agent solution and the rinsing water, which can be disposed to the drain or a wastewater treatment plant. The amount of effluent can be regarded as the minimum amount of wastewater when the recovery is planned according to this approach.

310 The minimum volume of wastewater is:

$$
V_{\text {wastewater }}=\frac{\pi d^{2}}{4} \cdot u_{0} \cdot t_{99, \text { plane }}-\frac{\pi d^{2}}{4} \cdot u_{0} \cdot t_{1, \text { plane }}=\frac{\pi d^{2}}{4} \cdot\left(u_{0} \cdot t_{99, \text { plane }}-u_{0} \cdot t_{1, \text { plane }}\right)
$$

311 As indicated by equation 4 , the values of $u_{0} \cdot t_{99, p l a n e}$ and $u_{0} \cdot t_{1, p l a n e}$ only depend on the inner pipe 312 diameter for a given pipe length. Therefore, the minimum volume of wastewater increases as well 313 when the pipe diameter increases.

314 3.6. Mixing zone length

315 Figure 9 shows the process when the agent is displaced by water in a $1 \mathrm{~m}$ pipe section within $2 \mathrm{~s}$. The 316 displacement occurs mainly in the axial direction. Mixing in radial direction is not significant when the 317 flow is in turbulent regimes (Chisti and Moo-Young, 1994). In this study, mixing length is defined as 318 the distance from the leading edge where the agent concentration is $99 \%$ to the trailing edge where 319 the agent concentration is $1 \%$. 
320 The study of mixing length is important for intermediate rinses, especially for long pipes. The usual 321 practice is to completely displace the cleaning agent $A$ by water before introducing another cleaning agent B. An alternative method is shown in Figure 10. Two cleaning agents can be synchronously introduced with a proper interval between the agents. A so called intermediate rinse length is the sum 324 of the mixing zone length of the agent $A$, the mixing zone length of the agent $B$ and an intermediate 325 length between two mixing zones. The intermediate length between two mixing zones can be 326 minimized in order to reduce water consumption. Thus, the minimum requirement of intermediate 327 rinsing water is the volume of two mixing zones which can be calculated from the mixing length.

328 Figure 11 demonstrates that the mixing length increases continuously with increasing rinsing time. The 329 leading edge (above 0 ) and trailing edge (below 0 ) are symmetrically located on two sides of the mid330 plane. Zhao et al. (2010) also observed that the increase in flow velocities contributed to greater 331 mixing lengths when simulating the displacement of a heavier liquid $A$ with another lighter liquid $B$ in a $33210 \mathrm{~m}$ straight pipe.

333 According to the penetration theory of Higbie (1935), the mixing length of different species is 334 dependent upon both the turbulent diffusivity and the contact time (van Elk et al., 2007; Zhao et al., 335 2010):

$$
l \propto 2 \sqrt{D_{t} \cdot t}
$$

336 where $l$ is the mixing length, $D_{t}$ is the turbulent diffusivity of the species. The right hand side term, $3372 \sqrt{D_{t} \cdot t}$, is called characteristic length in mixing (Ekambara and Joshi, 2004). By replacing the 338 turbulent diffusivity with the axial dispersion coefficient, equation 7 also applies to the axial mixing of 339 CFD results as shown in Figure 12. The idea behind the correlation is that the penetration theory 340 quantifies the component transfer using a similar error function as in equation 1 (Assar et al., 2014). 
341 On the basis of the correlation, it enables to predict the mixing lengths for longer rinsing time and

342 various flow rates and pipe diameters.

343 For a given pipe length, the contacting time can be assumed as $x / u_{0}$, which is the mean residence

344 time of rinsing water. Then the minimum requirement of intermediate rinsing water can be calculated 345 from the mixing length, as:

$$
V_{\text {inter. } \text { rinse }}=2 \cdot \frac{\pi d^{2}}{4} \cdot l=2 \cdot \frac{\pi d^{2}}{4} \cdot 3.29 \cdot\left(2 \sqrt{K \cdot x / u_{0}}\right)=3.29 \pi d^{2} \sqrt{K \cdot x / u_{0}}
$$

346 Under the flow conditions in this study, the second right hand side term in equation 3 dominates the

347 value of $K$. Therefore, equation 8 can be further simplified and approximated as:

$$
\begin{gathered}
V_{\text {inter. rinse }}=3.29 \pi d^{2} \sqrt{1.35\left(u_{0} d\right)^{0.875}(\mu / \rho)^{0.125} \cdot x / u_{0}} \\
=3.82 \pi \sqrt{u_{0}^{0.375} d^{4.875}(\mu / \rho)^{0.125} x}
\end{gathered}
$$

348 4. Application and further perspectives

349 4.1. Understand and control the process

350 The objective of any rinsing operation should be to completely remove the cleaning agent solution 351 using less water, shorter time and generating less wastewater. With this purpose in mind, the obtained 352 knowledge from this study can be categorized into two groups: the first type of knowledge is about 353 controlling the process, including the flow velocity, the minimum rinsing time and the times for 354 recovering the cleaning agent or rinsing water; the second type of knowledge is about understanding 355 the process, like the minimum water consumption, the minimum volume of wastewater, the recovered 356 volume of the cleaning agent and the minimum requirements of intermediate rinsing water.

357 Figure 13 presents an algorithm flowchart about how to apply the existing complex knowledge to 358 optimization of the rinsing process. Given the pipe diameter, flow velocity and pipe length, the minimum rinsing time can be calculated. In practical cases, the real rinsing time is normally set with 
360 safety margins, as it is not desired to risk producing inferior products due to unwise savings in 361 cleaning procedures. However, if the input rinsing time is much longer than the minimum required time, 362 it should be examined if an unnecessary waste of time and water is the case.

363 It is expensive to run CFD simulation for all conditions. But using the empirical or analytical equations 364 derived from CFD results is practical. Equation 4 calculates the time to stop the recovery of cleaning 365 agent and the time to start the recovery of rinsing water. Correspondingly, the effluent between the 366 two time points is regarded as wastewater, the minimum volume of which can be predicted with help 367 of equation 6 . If the real volume of wastewater is more than the minimum, it means the recovery 368 efficiency can be higher by adjusting the recovery time. On the contrary, if the volume of wastewater is 369 less than the minimum, it leads to the potential risk of excessive recovery. For example, the recovered 370 cleaning agent has been diluted by the rinsing water, or the reused rinsing water has been "polluted" 371 by the cleaning agent. If it is the intermediate rinse between two cleaning agent solutions, the 372 minimum volume of intermediate rinsing water can be calculated according to equation 8 or 9 .

373 4.2. A case study of rinsing a $24 \mathrm{~m}$ straight pipe with inner diameter $100 \mathrm{~mm}$

374 The above results are extended to analyze the rinse of a $24 \mathrm{~m}$ straight pipe with inner diameter 100 $375 \mathrm{~mm}$. The mean flow velocity is $1-2 \mathrm{~m} / \mathrm{s}$. The set time of the rinsing step is assumed to be $1.5 \cdot x / u_{0}$. 376 In industrial practice, the rinsing time is usually set based on experience, which can thus be over or 377 below 1.5 times the residence time. The density and dynamic viscosity are assumed to be $997 \mathrm{~kg} / \mathrm{m}^{3}$ 378 and $8.899 \times 10^{-4} \mathrm{~kg} /(\mathrm{m} \cdot \mathrm{s})$, and are assumed the same for the agent solution and the rinsing water.

379 Table 3 summarizes the results, which have been produced using the algorithm summarized in Figure 380 13. The calculated minimum rinsing time based on a fixed plane is $11.2 \%$ larger than the minimum 381 rinsing time calculated based on the volume. The set time is 1.36 times the $t_{99, \text { volume }}$. The increase in 382 flow velocity can shorten the rinsing time. However, the consumption of rinsing water, the recovery of 
cleaning agent and the generation of wastewater are independent of the flow velocities. The recovery 384 of cleaning agent is up to $89.3 \%$ of the volume. If it is the intermediate rinse, the increase in flow velocity slightly reduces the minimum requirement of intermediate rinsing water. An important result is that the implementation of synchronous intermediate rinse saves $\sim 55 \%$ of water compared with the minimum requirement to replace all agent components from the pipe.

\subsection{Effects of complex element geometries}

This study simulates the displacement process in straight pipes. However, a complete transfer line consists of various elements, such as bends, T-joints, expansions, contractions and valves. Graßhoff (1983) studied the displacement of one liquid with another liquid in three types of T-joints: (1) direct entrance and exit with a perpendicular dead zone; (2) perpendicular entrance and exit with the dead zone extending the entrance stream; and, (3) perpendicular entrance and exit with the dead zone reversing the exit stream. A local sensor was installed at the end of the dead zone. With the increase in the dead zone length from $d$ to $10 d$, the displacement time $\left(t_{99}\right)$ determined by the local sensor varied from seconds to ten thousands of seconds. Thus, the time to completely remove the cleaning agent from a long dead zone is much longer than for rinsing straight pipes.

CFD is a powerful tool to study the hygienic design of such elements. According to the European Hygienic Engineering \& Design Group (EHEDG) Testing and Certification guideline, CFD is currently 400 the only alternative to test the scalability of difference sizes of the same piece of equipment, apart 401 from the evaluation based on a design review and CIP test (EHEDG.org, 2016). CFD simulations of 402 the intermediate and final rinses serve as a supplement to previous studies where water is applied as 403 a medium to dissolve or remove soils from the surfaces (Asteriadou et al., 2009, 2007, 2006). This 404 article boosts the confidence to implement such CFD simulations of the displacement process for more complex element geometries which are more commonly used in practice. 
407 In this paper, CFD is used to simulate the intermediate and final rinses of straight horizontal pipes in

408 CIP applications. Axial mixing and displacement of agent solutions by water are studied and compared 409 with the Taylor model. The proposed CFD model for description of agent concentrations at varying 410 time points and locations in the pipe is found to give an excellent agreement with the Taylor analytical 411 model.

412 The key findings in the presented work are summarized in the following:

1) The displacement times are dependent on the pipe diameters and flow velocities. The product of the displacement time and the mean flow velocity can be correlated by a power function with inner pipe diameter as independent variable.

2) The minimum water consumption for completely rinsing a pipe is slightly larger than the pipe volume. The minimum water consumption is not much influenced by changing flow velocities when the flows are fully turbulent.

3) A practical rinsing step can be controlled based on downstream measurement and rinsing stops when the measurement reaches the pre-defined criteria. However, the set time is still longer than required. The water consumption is still more than the minimum requirement in order to reduce contamination risks.

4) The minimum volume of wastewater can be predicted from the displacement times, and is independent of the flow velocity.

5) Radial mixing is not significant during the displacement process. The mixing length varies with the pipe diameters, flow velocities and rinsing time. The values of the mixing lengths are proportional to the characteristic length $(2 \sqrt{K \cdot t})$, which can be applied to calculate the minimum requirement of intermediate rinsing water. 
429 The observations in this work can help to optimize the control of the rinsing step in terms of the flow 430 velocity, the rinsing time and the recovery plans of the cleaning agent and rinsing water. A case study 431 of rinsing a $24 \mathrm{~m}$ straight pipe with inner diameter $100 \mathrm{~mm}$ reveals that the recovery of cleaning agent 432 can be up to $89.3 \%$ of the volume and the saving of intermediate rinsing water can be at least $55 \%$. 433 The successful simulation of the intermediate and final rinses of straight pipes builds confidence for 434 future studies to simulate the displacement process for more complex geometries and improve the 435 hygienic design and the CIP cleaning of different pipe elements.

436 Acknowledgements

437 This paper results from the DRIP (Danish partnership for Resource and water efficient Industrial food 438 Production) project. We acknowledge that this work is partly funded by the Innovation Fund Denmark 439 (IFD) under contract No. 5107-00003B, and by the Technical University of Denmark (DTU). 


\section{References}

Assar, M., Abolghasemi, H., Hamane, M.R., Hashemi, S.J., Fatoorehchi, H., 2014. A new approach to analyze entrance region mass transfer within a falling film. Heat Mass Transf. 50, 651-660. doi:10.1007/s00231-013-1263-3

Asteriadou, K., Hasting, A.P.M., Bird, M.R., Melrose, J., 2009. Exploring CFD solutions for coexisting flow regimes in a T-piece. Chem. Eng. Technol. 32, 948-955. doi:10.1002/ceat.200900060

Asteriadou, K., Hasting, A.P.M., Bird, M.R., Melrose, J., 2006. Computational Fluid Dynamics for the Prediction of Temperature Profiles and Hygienic Design in the Food Industry. Food Bioprod. Process. 84, 157-163. doi:10.1205/fbp.04261

Asteriadou, K., Hasting, T., Bird, M., Melrose, J., 2007. Predicting cleaning of equipment using computational fluid dynamics. J. Food Process Eng. 30, 88-105. doi:10.1111/j.17454530.2007.00103.x

Bailey, J.E., Ollis, D.F., 1986. Biochemical Engineering Fundamentals, 2nd ed. McGraw-Hill Education, Singapore.

Chen, L., Chen, R., Yin, H., Sui, J., Lin, H., 2012. Cleaning in place with onsite-generated electrolysed oxidizing water for water-saving disinfection in breweries. J. Inst. Brew. 118, 401-405. doi:10.1002/jib.56

Chisti, Y., Moo-Young, M., 1994. Clean-in-place systems for industrial bioreactors: Design, validation and operation. J. Ind. Microbiol. 13, 201-207. doi:10.1007/BF01569748

EHEDG.org, 2016. Frequently Asked Questions about EHEDG Testing and Certification [WWW Document]. URL http://www.ehedg.org/index.php?nr=301\&lang=en (accessed 10.17.16).

Ekambara, K., Joshi, J.B., 2004. Axial mixing in laminar pipe flows. Chem. Eng. Sci. 59, 3929-3944. doi:10.1016/j.ces.2004.05.025

Friis, A., Jensen, B.B.B., 2002. Prediction of hygiene in food processing equipment using flow modelling. Food Bioprod. Process. 80, 281-285. doi:10.1205/096030802321154781

Graßhoff, A., 1983. Toträume in CIP-gereinigten Rohrleitungssystemen. Dtsch. Milchwirtschaft 13, 407-412.

Henningsson, M., Regner, M., Östergren, K., Trägårdh, C., Dejmek, P., 2007. CFD simulation and ERT visualization of the displacement of yoghurt by water on industrial scale. J. Food Eng. 80, 166-175. doi:10.1016/j.jfoodeng.2006.04.058

Higbie, R., 1935. The rate of absorption of a pure gas into still liquid during short periods of exposure. Trans. Am. Inst. Chem. Eng. 31, 365-389.

Jensen, B.B.B., 2007. Numerical study of influence of inlet turbulence parameters on turbulence intensity in the flow domain: incompressible flow in pipe system. Proc. Inst. Mech. Eng. Part E J. Process Mech. Eng. 221, 177-186. doi:10.1243/09544089JPME124

Jensen, B.B.B., Benezech, T., Legentilhomme, P., Lelievre, C., Friis, A., 2006. Predicting cleaning: 
Estimate fluctuations in signal from electrochemical wall shear stress measurements using CFD, in: Fouling, Cleaning \& Disinfection in Food Processing. Department of Chemical Engineering, University of Cambridge, Cambridge, UK.

Jensen, B.B.B., Friis, A., 2005. Predicting the cleanability of mix-proof valves by use of wall shear stress. J. Food Process Eng. 28, 89-106. doi:10.1111/j.1745-4530.2005.00370.x

Jensen, B.B.B., Friis, A., 2004. Prediction of flow in mix-proof valve by use of CFD - validation by LDA. J. Food Process Eng. 27, 65-85. doi:10.1111/j.1745-4530.2004.tb00623.x

Jurado-Alameda, E., Altmajer Vaz, D., Garcia Román, M., Siqueira Curto Valle, R.D.C., 2016. Cleaning of starchy soils in Clean-in-Place (CIP) systems: relationship between contact angle and detergency. J. Dispers. Sci. Technol. 37, 317-325. doi:10.1080/01932691.2014.1003223

Lelieveld, H.L.M., Mostert, M.A., Holah, J., 2005. Handbook of hygiene control in the food industry. Woodhead Publishing Limited, Cambridge, UK.

Levenspiel, O., 1958. Longitudinal mixing of fluids flowing in circular pipes. Ind. Eng. Chem. 50, 343346. doi:10.1021/ie50579a034

Li, G., Hall, P., Miles, N., Wu, T., 2015a. Improving the efficiency of "Clean-In-Place" procedures using a four-lobed swirl pipe: A numerical investigation. Comput. Fluids 108, 116-128. doi:10.1016/j.compfluid.2014.11.032

Li, G., Hall, P., Miles, N., Wu, T., 2015b. Optimization of a four-lobed swirl pipe for Clean-In-Place procedures. Int. J. Environ. 9, 689-697. doi:10.13140/RG.2.1.4838.0004

Palabiyik, I., 2013. Investigation of fluid mechanical removal in the cleaning process. School of Chemical Engineering, PhD thesis, University of Birmingham.

Palabiyik, I., Yilmaz, M.T., Fryer, P.J., Robbins, P.T., Toker, Ö.S., 2015. Minimising the environmental footprint of industrial-scaled cleaning processes by optimisation of a novel clean-in-place system protocol. J. Clean. Prod. 108, 1009-1018. doi:10.1016/j.jclepro.2015.07.114

Salmi, T., Mikkola, J.-P., Warna, P., 2010. Chemical reaction engineering and reactor technology. CRC Press, Boca Raton.

Schöler, M., Föste, H., Helbig, M., Gottwald, A., Friedrichs, J., Werner, C., Augustin, W., Scholl, S., Majschak, J.-P., 2012. Local analysis of cleaning mechanisms in CIP processes. Food Bioprod. Process. 90, 858-866. doi:10.1016/j.fbp.2012.06.005

Sugiharto, Stegowski, Z., Furman, L., Su'ud, Z., Kurniadi, R., Waris, A., Abidin, Z., 2013. Dispersion determination in a turbulent pipe flow using radiotracer data and CFD analysis. Comput. Fluids 79, 77-81. doi:10.1016/j.compfluid.2013.03.009

Tamime, A.Y., 2008. Cleaning-in-Place: Dairy, Food and Beverage Operations, 3rd ed. Blackwell, Ayr, UK.

Taylor, G.I., 1953. Dispersion of soluble matter in solvent flowing slowly through a tube. Proceeding R. Soc. London, Ser. A, Math. Phys. Sci. 219, 186-203. doi:10.1098/rspa.1953.0139

van Elk, E.P., Knaap, M.C., Versteeg, G.F., 2007. Application of the penetration theory for gas-liquid 
mass transfer without liquid bulk: differences with systems with a bulk. Chem. Eng. Res. Des. 85, 516-524. doi:10.1205/cherd06066

Wiklund, J., Stading, M., Trägårdh, C., 2010. Monitoring liquid displacement of model and industrial fluids in pipes by in-line ultrasonic rheometry. J. Food Eng. 99, 330-337. doi:10.1016/j.jfoodeng.2010.03.011

Wilcox, D.C., 2006. Turbulence Modeling for CFD, 3rd ed. DCW Industries, La Canada, CA.

Yang, J., 2017. A review of cleaning-in-place: industrial challenges and practices, in: Dam-Johansen, K., Forero-Hernández, H., Szabo, P. (Eds.), Graduate Schools Yearbook 2016. Technical University of Denmark, Lyngby, pp. 151-152.

Zhao, L., Derksen, J., Gupta, R., 2010. Simulations of axial mixing of liquids in a long horizontal pipe for industrial applications. Energy \& Fuels 24, 5844-5850. doi:10.1021/ef100846r 


\section{Figure captions:}

Figure 1. (A) The cleaning time of each step and (B) the costs in a CIP procedure of transfer pipes in a brewery. The cleaning is performed at room temperature. The recovery $(\sim 95 \%)$ of cleaning chemicals has been considered in the calculation of the costs. (Reproduced with permission of Carlsberg, Fredericia, Denmark)

Figure 2. Structured mesh of the cross section of the pipe with diameter $40.90 \mathrm{~mm}$ (DN 40). The near-wall meshes were enhanced by fine layers. The geometry was simplified as a quarter section of the pipe in order to save computational time. The mesh element in the pipe center (at the bottom-left corner) was nearly cuboid.

Figure 3. Description of the distribution of agent component within the pipe at $t=0$. The agent components were dissolved in water with a concentration of $1 \mathrm{~kg} / \mathrm{m}^{3}$ at $x \geq 0 \mathrm{~m}$. Water was flushed from $x=-3 \mathrm{~m}$. Such treatment eliminated the entrance effect at $x=0$ under which the inlet flow was not fully turbulent.

Figure 4. Near-wall turbulence intensity ( $1 \mathrm{~mm}$ from the wall) for different model cases. The inner pipe diameter is $40.90 \mathrm{~mm}$ (DN 40), the flow velocity is $1.5 \mathrm{~m} / \mathrm{s}$. The parameters of the 7 model cases are listed in Table 1 . Cases 2, 6 and 7 are designed for the mesh independence study. Cases $1-5$ are designed for the study of inlet boundary conditions. Case 2 is the reference which is the selected mesh.

Figure 5. Average agent concentrations at the different mid-planes $\left(x=u_{0} \cdot t\right)$ for model cases as described in Table 1. The inner pipe diameter is $40.90 \mathrm{~mm}$ (DN 40), the flow velocity is $1.5 \mathrm{~m} / \mathrm{s}$. Equation 1 indicates that $C_{m}=0.5 \mathrm{~kg} / \mathrm{m}^{3}$ at $x=u_{0} \cdot t$. Cases $1-5$ result in the same average agent concentrations (with precision $0.00001 \mathrm{~kg} / \mathrm{m}^{3}$ ), which are displayed as overlapping symbols.

Figure 6. Comparison of the Taylor model and the CFD simulations at $1.5 \mathrm{~m} / \mathrm{s}$ of flow velocity for (A) a fixed distance of $15 \mathrm{~m}$ with varied rinsing time, and (B) a fixed rinsing time of $10 \mathrm{~s}$ with varied distance.

Figure 7. Axial velocity and turbulent kinetic energy at the distance of $15 \mathrm{~m}$ and for a mean flow velocity of 1.5 $\mathrm{m} / \mathrm{s}$ for different pipe diameters $(R e=26500 \sim 259000) . r / R$ is the dimensionless distance from the center of the pipe to the wall. The values of $u_{x}$ and $k$ quantify the intensity of convection in the axial direction when the radial velocity and tangential velocities are not significant in the pipe.

Figure 8. The product of displacement time and flow velocity for different pipe lengths. The marker values and error bars (too small to be seen) are from the CFD models for the simulated pipe diameters, representing the average and standard deviation of $t_{1 \text { or } 99} \cdot u_{0}$ at three flow velocities. The curves represent the values which are calculated by the power function in equation 7 .

Figure 9. Agent distribution in a $1 \mathrm{~m}$ pipe section at different rinsing times. The inner pipe diameter is $26.64 \mathrm{~mm}$ (DN $25 \mathrm{~mm}$ ), and the flow velocity is $1.5 \mathrm{~m} / \mathrm{s}$.

Figure 10. Intermediate rinse length between two cleaning agents. The intermediate rinse length equals the sum of the mixing zone of agent $\mathrm{A}$, the mixing zone of agent $\mathrm{B}$ and an intermediate length between two mixing zones. The minimum intermediate rinse length is when the intermediate length between two mixing zones is zero.

Figure 11. Dynamic mixing length of the $77.90 \mathrm{~mm}$ diameter (DN 80) pipe at $1 \mathrm{~m} / \mathrm{s}$ and $2 \mathrm{~m} / \mathrm{s} . \Delta x$ is the relative position of the leading edge $(+)$ and the trailing edge $(-)$ to the mid-plane $\left(x=u_{0} \cdot t\right)$ 
Figure 12. Correlation of the mixing length with the characteristic length, $2 \sqrt{K \cdot t}$. The mixing lengths of different pipe diameters at different flow velocities are proportional to the characteristic length, which can be expressed by a first order equation with high correlation coefficient.

Figure 13. The algorithm for understanding and controlling the rinse of straight pipes based on the findings in this study. The algorithm is only valid if the flow is turbulent. 


\section{Tables and captionss}

Table 1. Parameters for the mesh study and for the influence of turbulence intensity and turbulence length scale. The inner pipe diameter is $40.90 \mathrm{~mm}$ (DN 40), the flow velocity is $1.5 \mathrm{~m} / \mathrm{s}$. Case 2 is the reference case which is selected for other studies.

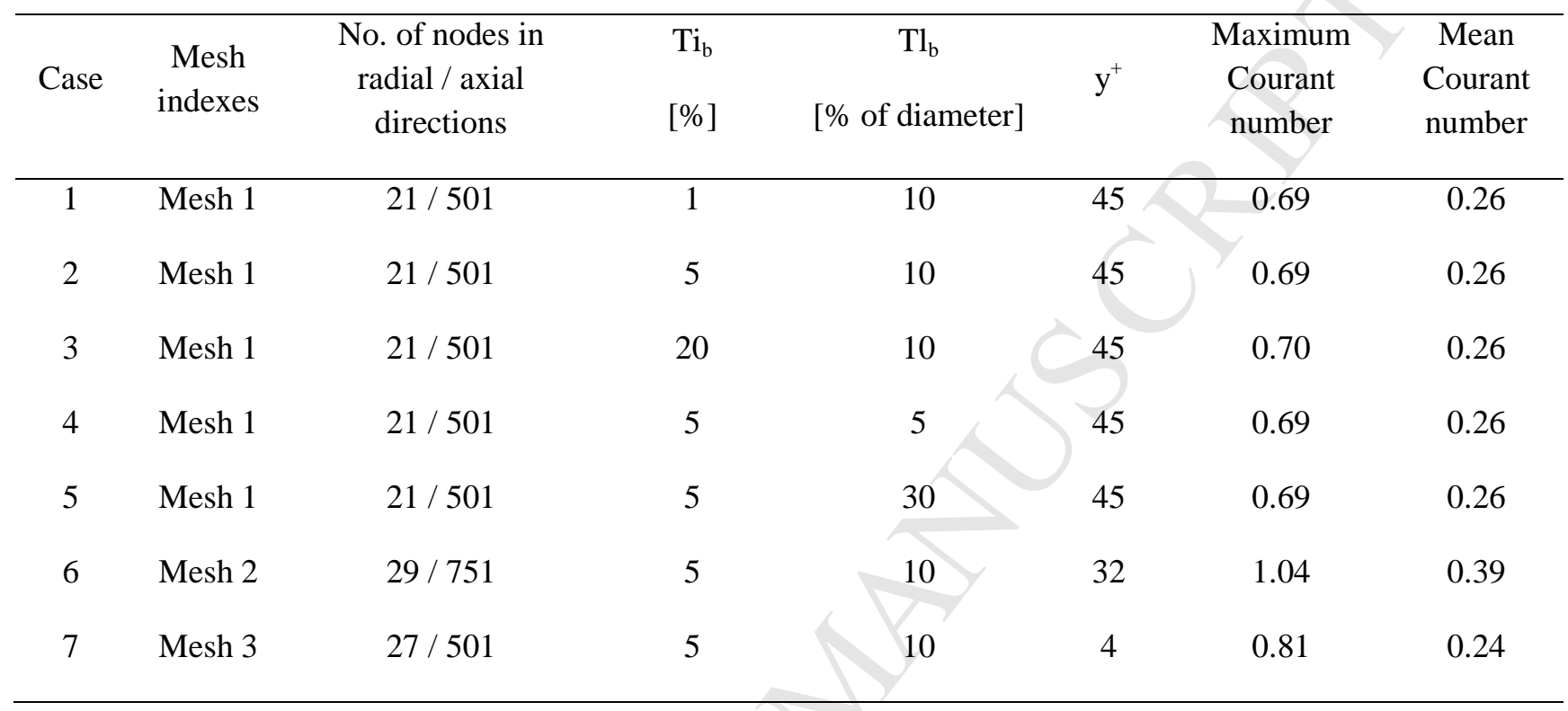


Table 2. Correlation parameters of the product of displacement time and flow velocity for different pipe lengths by the power function as equation 7 . The unit of inner pipe diameter should be meter. Depending on the practical cases, the correlation parameters of other pipe lengths can also be extracted from the CFD simulation results.

\begin{tabular}{ccccc}
\hline$x,[m]$ & $t,[s]$ & $\alpha,\left[m^{1-\beta}\right]$ & $\beta$ & $\mathrm{R}^{2}$ \\
\hline \multirow{2}{*}{2} & $t_{1, \text { plane }}$ & 1.01 & -0.121 & 0.998 \\
& $t_{99, \text { plane }}$ & 3.83 & 0.107 & 0.963 \\
& $t_{99, \text { volume }}$ & 3.03 & 0.0788 & 0.966 \\
\hline \multirow{2}{*}{15} & $t_{1, \text { plane }}$ & 11.7 & -0.0456 & 0.989 \\
& $t_{99, \text { plane }}$ & 19.1 & 0.0422 & 0.978 \\
& $t_{99, \text { volume }}$ & 16.4 & 0.0212 & 0.970 \\
\hline \multirow{2}{*}{24} & $t_{1, \text { plane }}$ & 19.8 & -0.0354 & 0.996 \\
& $t_{99, \text { plane }}$ & 29.1 & 0.0337 & 0.980 \\
& $t_{99, \text { volume }}$ & 25.5 & 0.0152 & 0.971 \\
\hline
\end{tabular}


Table 3. Result summary of the case study for rinsing a $24 \mathrm{~m}$ straight pipe with inner diameter $100 \mathrm{~mm}$. The analysis follows the algorithm depicted in Figure 15.

\begin{tabular}{|c|c|c|c|}
\hline$u_{0},[\mathrm{~m} / \mathrm{s}]$ & 1 & 1.5 & 2 \\
\hline$R e$ & 112035 & 168053 & 224070 \\
\hline Turbulence or not? & Yes & Yes & Yes \\
\hline$K,\left[\mathrm{~m}^{2} / \mathrm{s}\right]$ & 0.0316 & 0.0450 & 0.0579 \\
\hline$t_{1, \text { plane }},[\mathrm{s}]$ & 21.43 & 14.29 & 10.72 \\
\hline$t_{99, \text { plane }},[\mathrm{s}]$ & 31.43 & 20.95 & 15.71 \\
\hline$t_{99, \text { volume }},[\mathrm{s}]$ & 26.42 & 17.62 & 13.21 \\
\hline$f_{\text {plane }}$ & 1.038 & 1.038 & 1.038 \\
\hline$f_{\text {volume }}$ & 1.154 & 1.154 & 1.154 \\
\hline$V_{\text {min }, \text { plane }},\left[\mathrm{m}^{3}\right]$ & 0.218 & 0.218 & 0.218 \\
\hline$V_{\text {min,volume }},\left[\mathrm{m}^{3}\right]$ & 0.196 & 0.196 & 0.196 \\
\hline$V_{\text {min,plane }} / V_{\text {min,volume }}$ & 1.112 & 1.112 & 1.112 \\
\hline Real rinsing time $t=1.5 \cdot x / u_{0}$, & 36 & 24 & 18 \\
\hline$t / t_{99, \text { volume }}$ & 1.36 & 1.36 & 1.36 \\
\hline Time to start the recovery of rinsing water, $[\mathrm{s}]$ & 31.43 & 20.95 & 15.71 \\
\hline Real water consumption $V_{t},\left[\mathrm{~m}^{3}\right]$ & 0.283 & 0.283 & 0.283 \\
\hline Recovery of cleaning agent solution, $\left[\mathrm{m}^{3}\right]$ & 0.168 & 0.168 & 0.168 \\
\hline Recovery percentage of cleaning agent solution, [\%] & 89.3 & 89.3 & 89.3 \\
\hline Minimum amount of wastewater, $\left[\mathrm{m}^{3}\right]$ & 0.079 & 0.079 & 0.079 \\
\hline$V_{\text {inter. } \text { rinse }},\left[\mathrm{m}^{3}\right]$ & 0.090 & 0.088 & 0.086 \\
\hline$\left(V_{\text {min,volume }}-V_{\text {inter. rinse }}\right) / V_{\text {min,volume }}$ & 0.539 & 0.551 & 0.559 \\
\hline
\end{tabular}




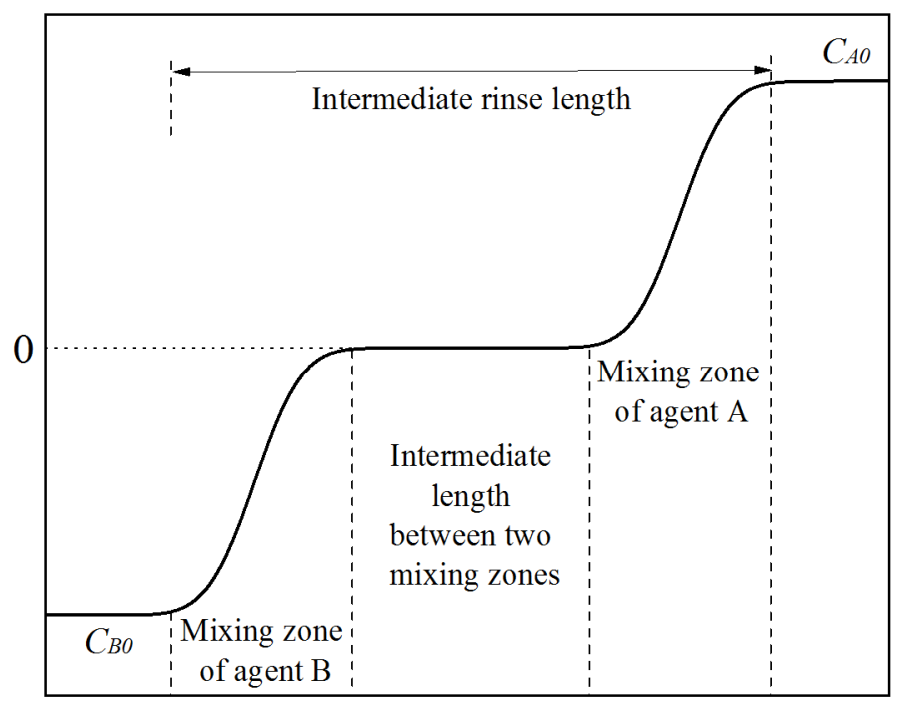

Flow 


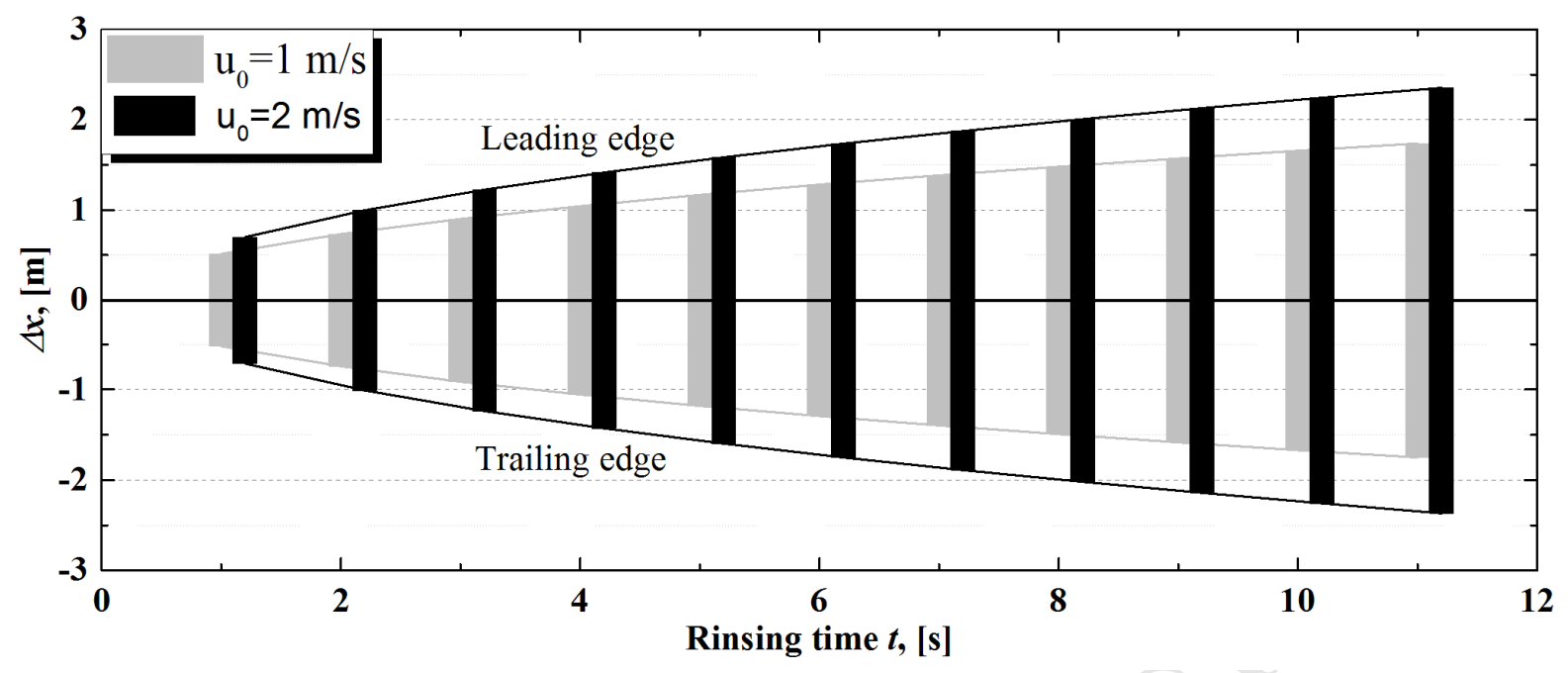




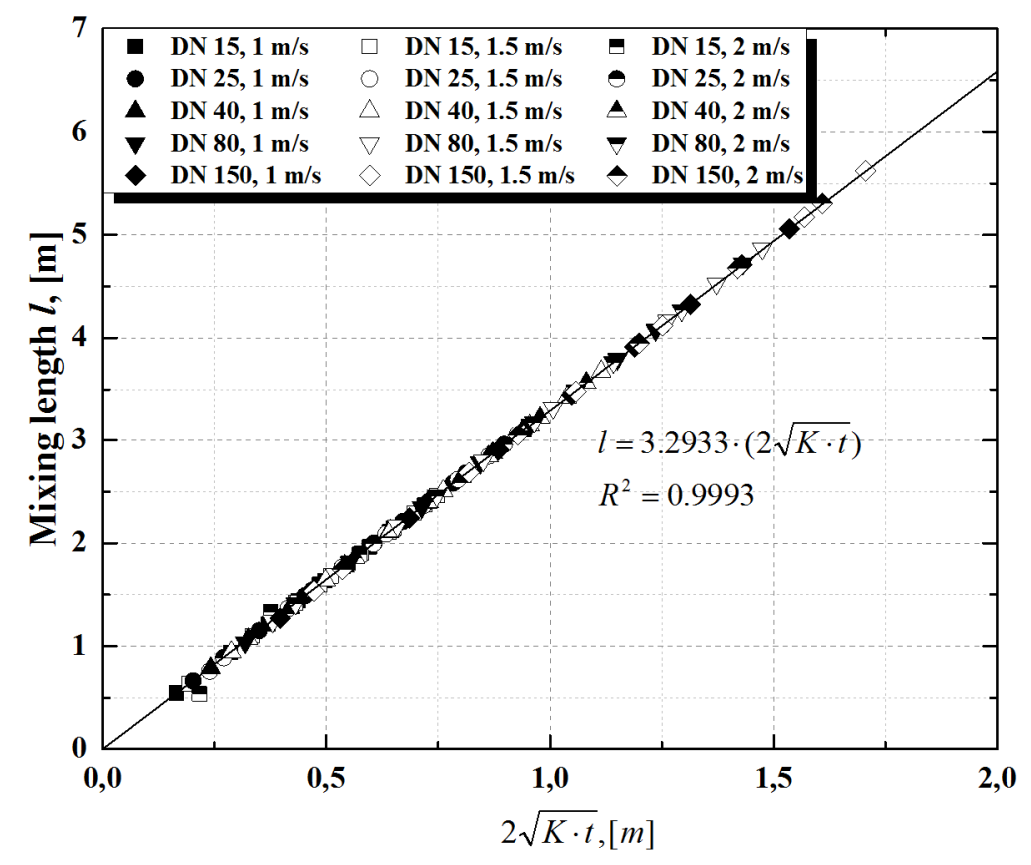




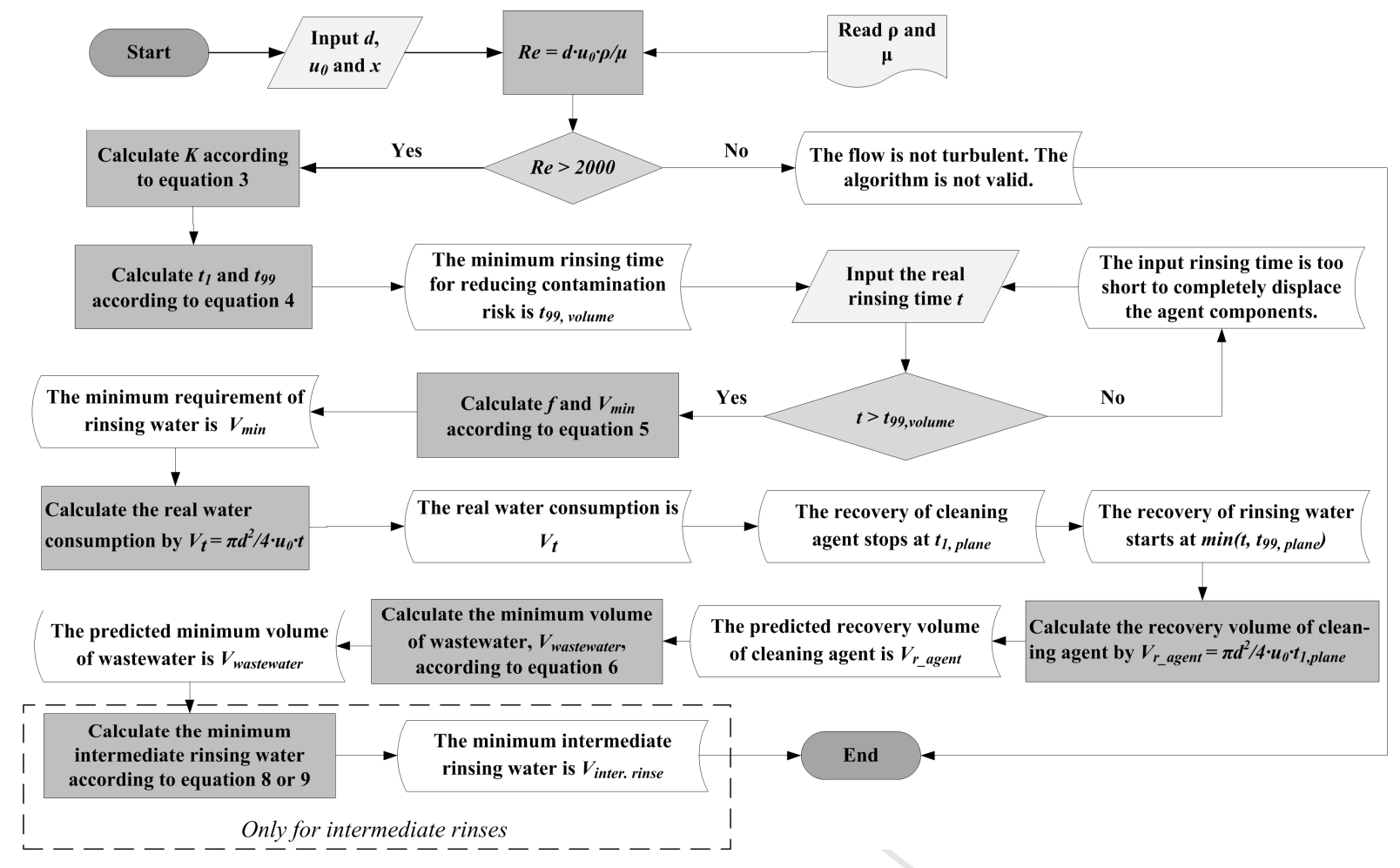




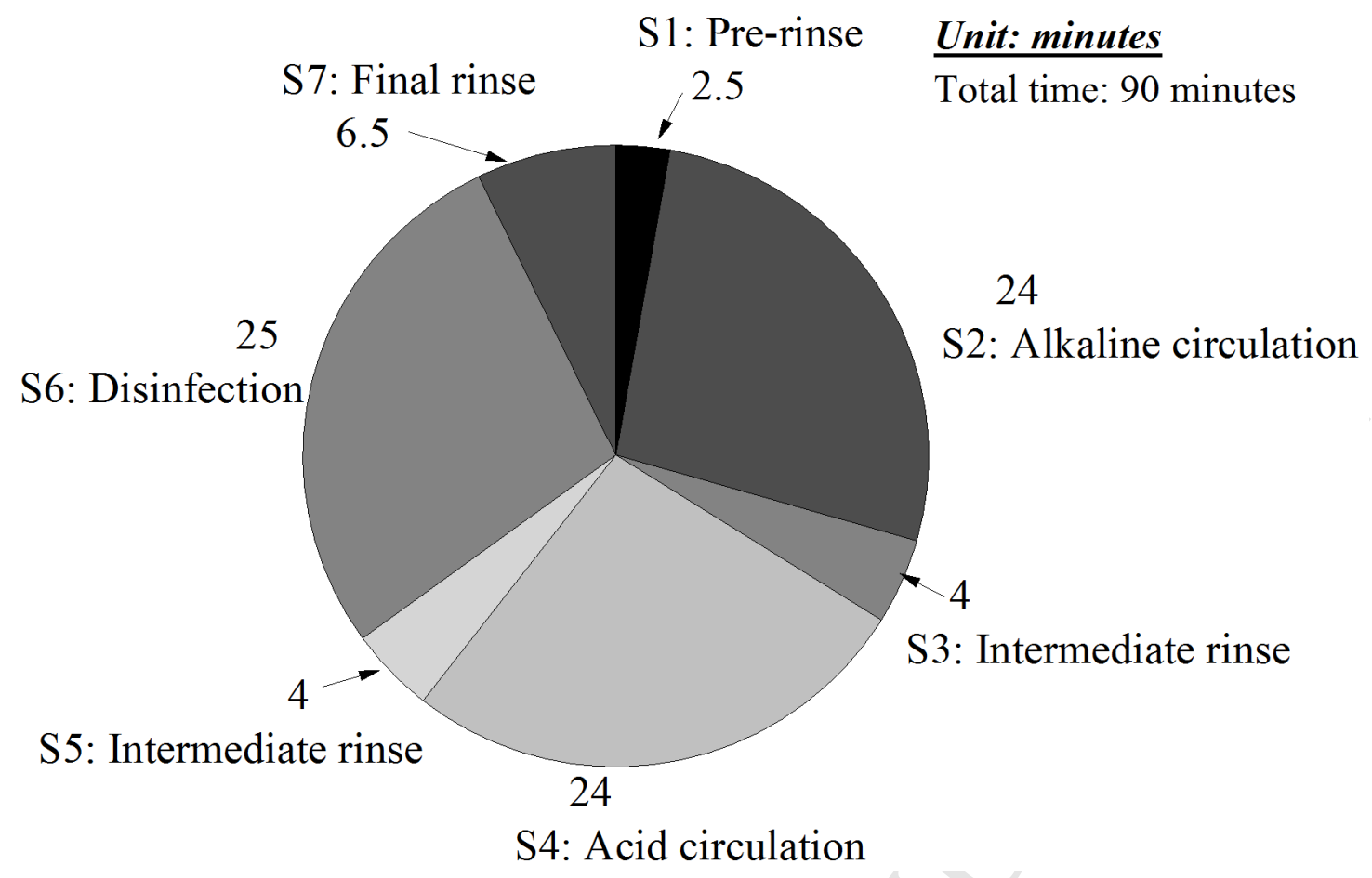




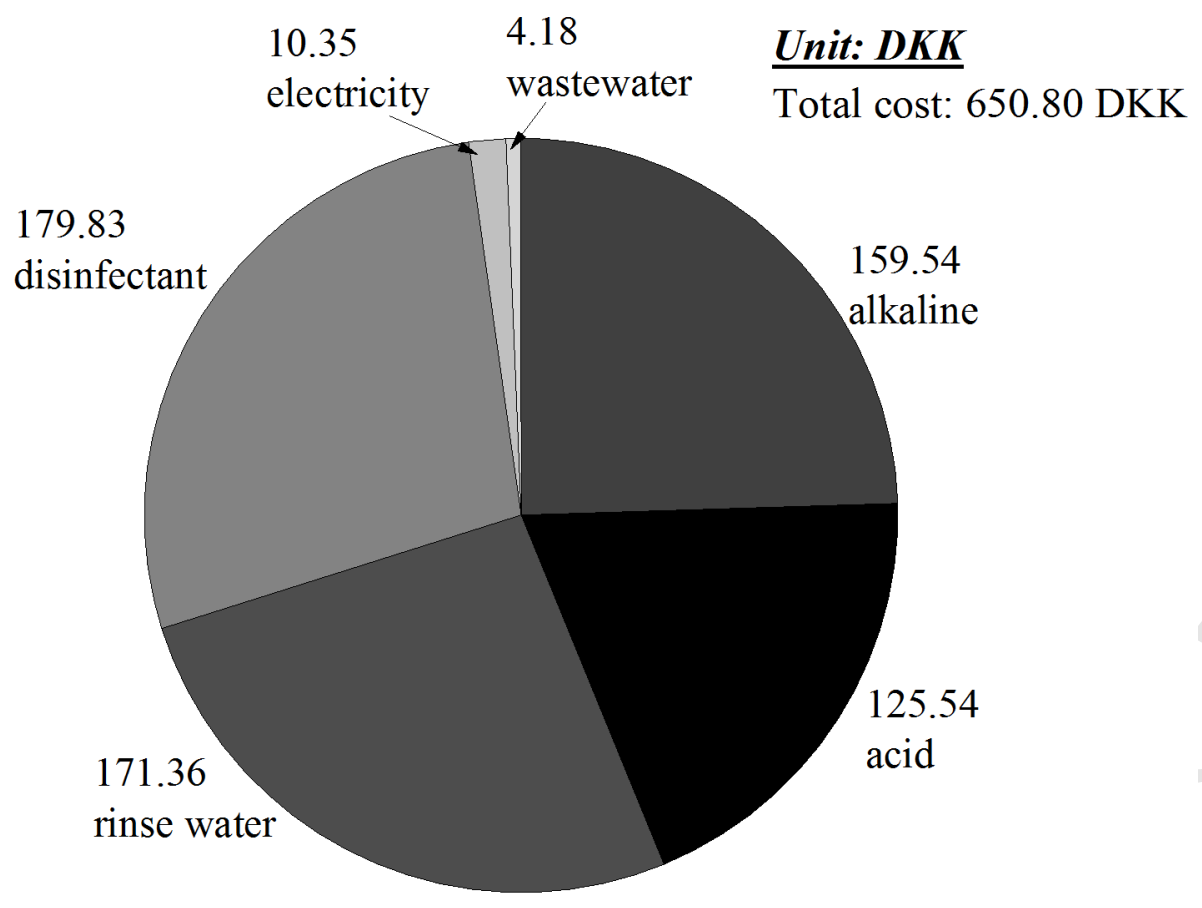




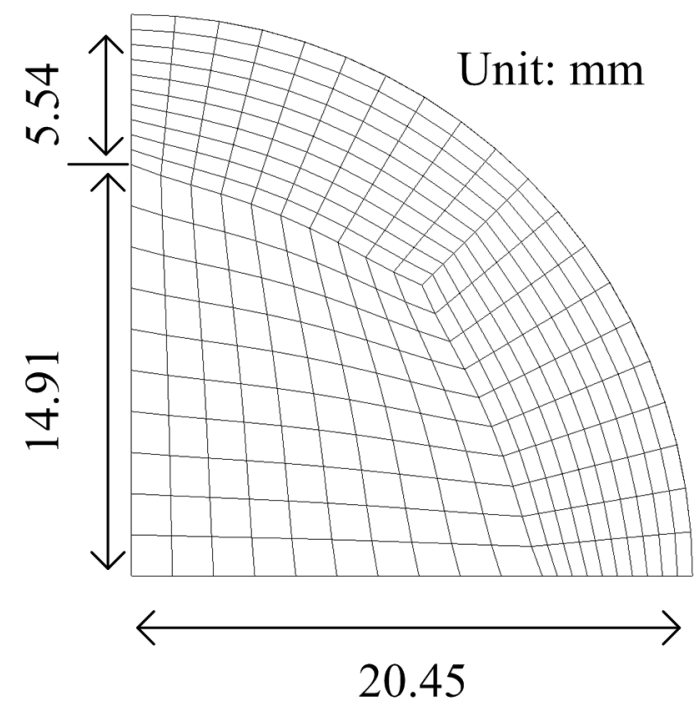




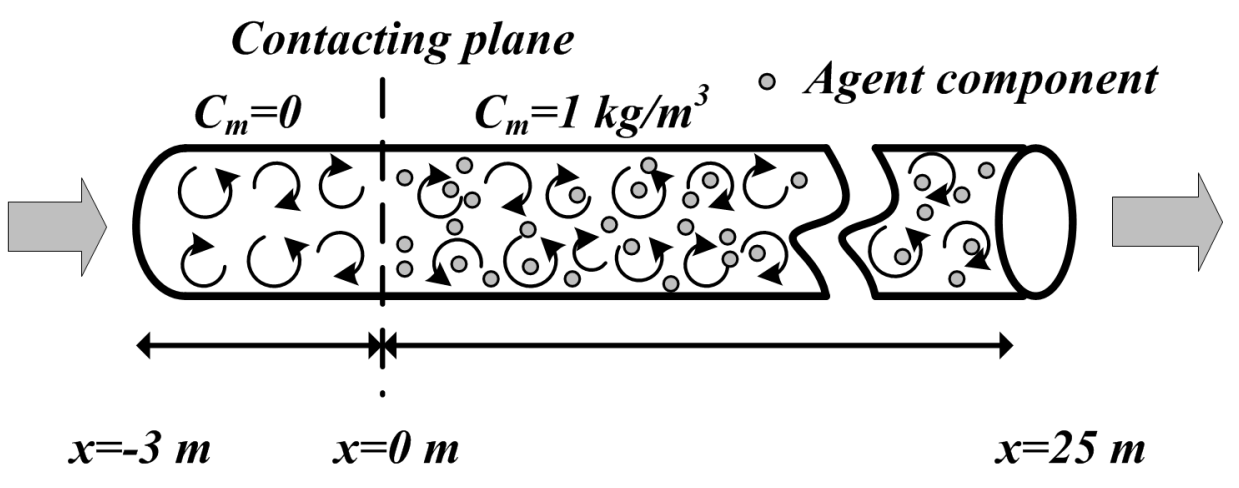




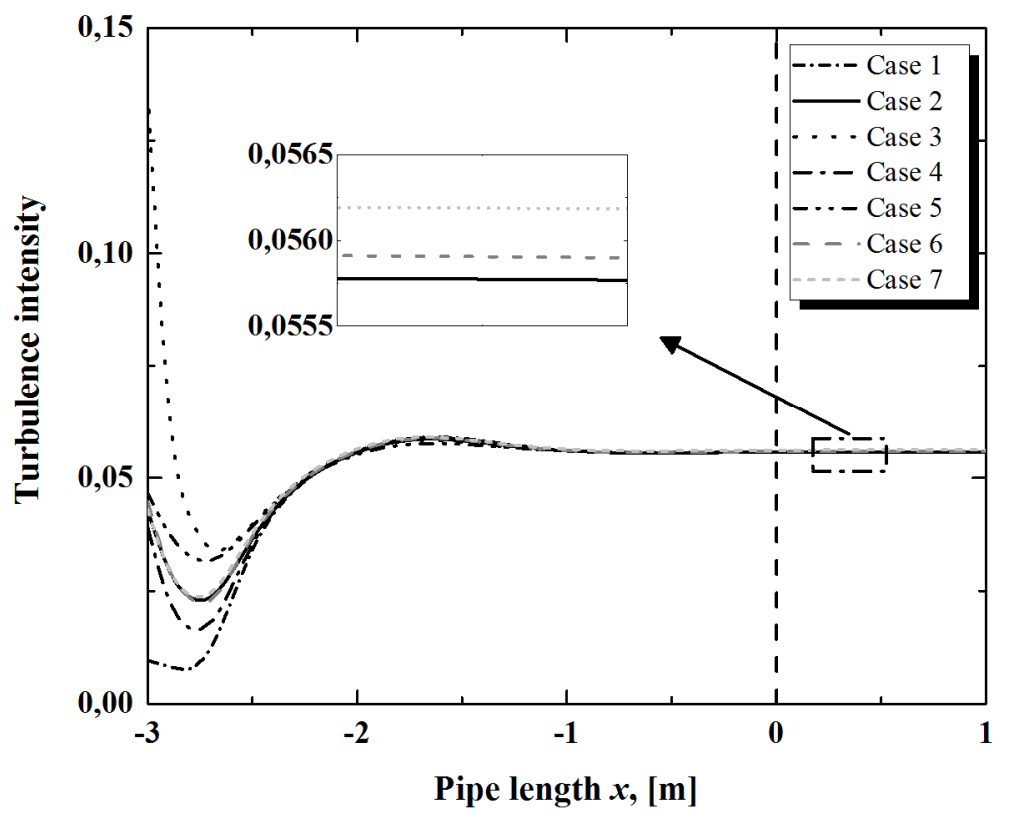




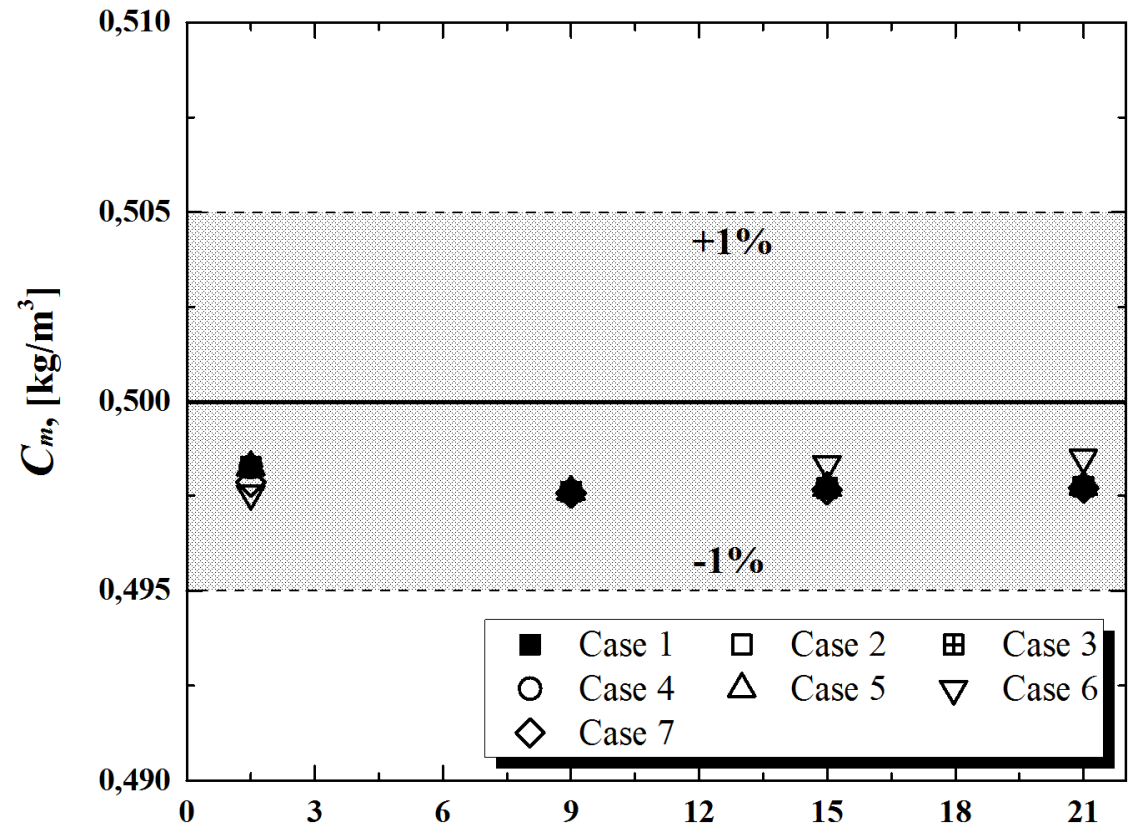

Pipe length $x,[\mathrm{~m}]$ 


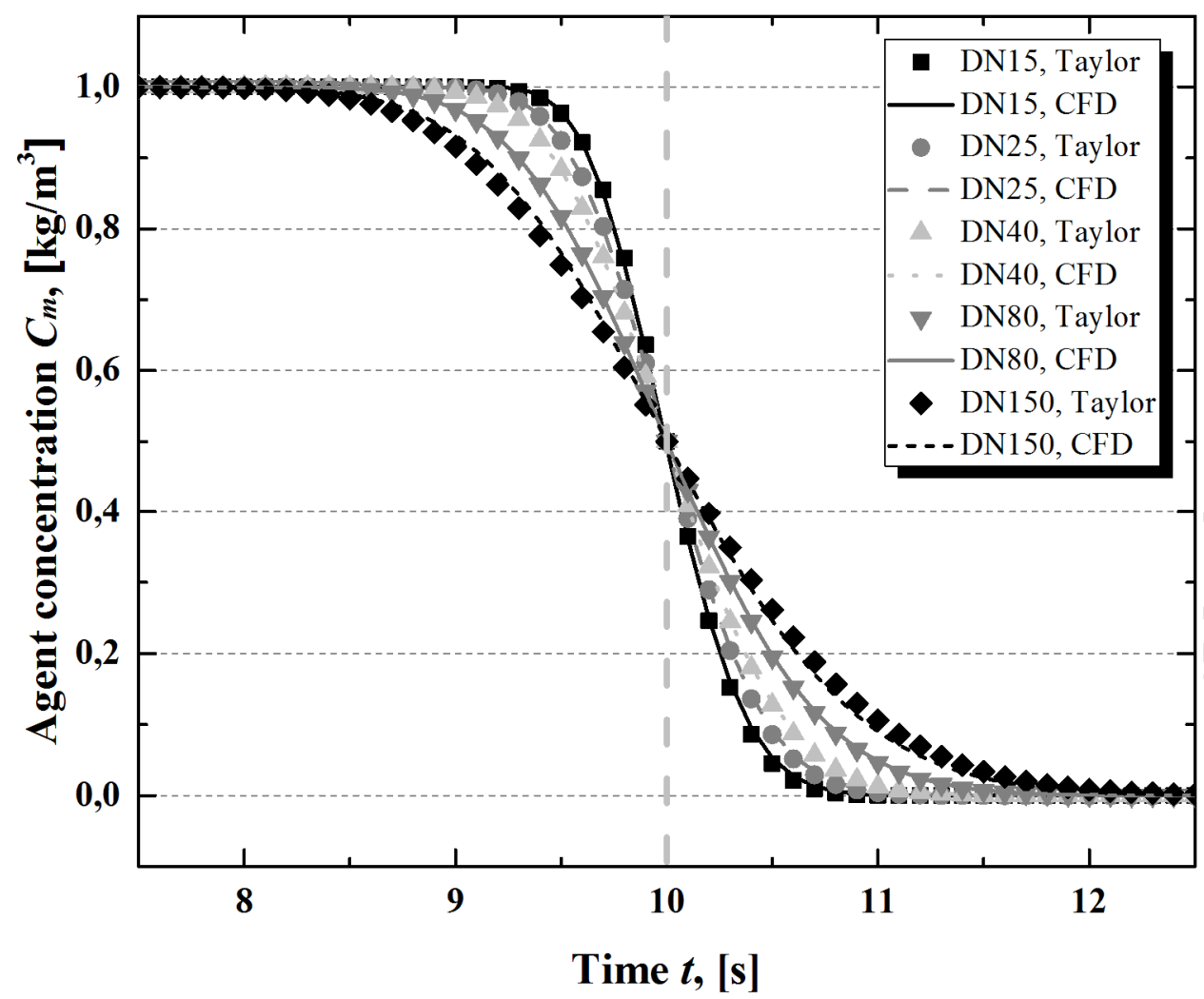




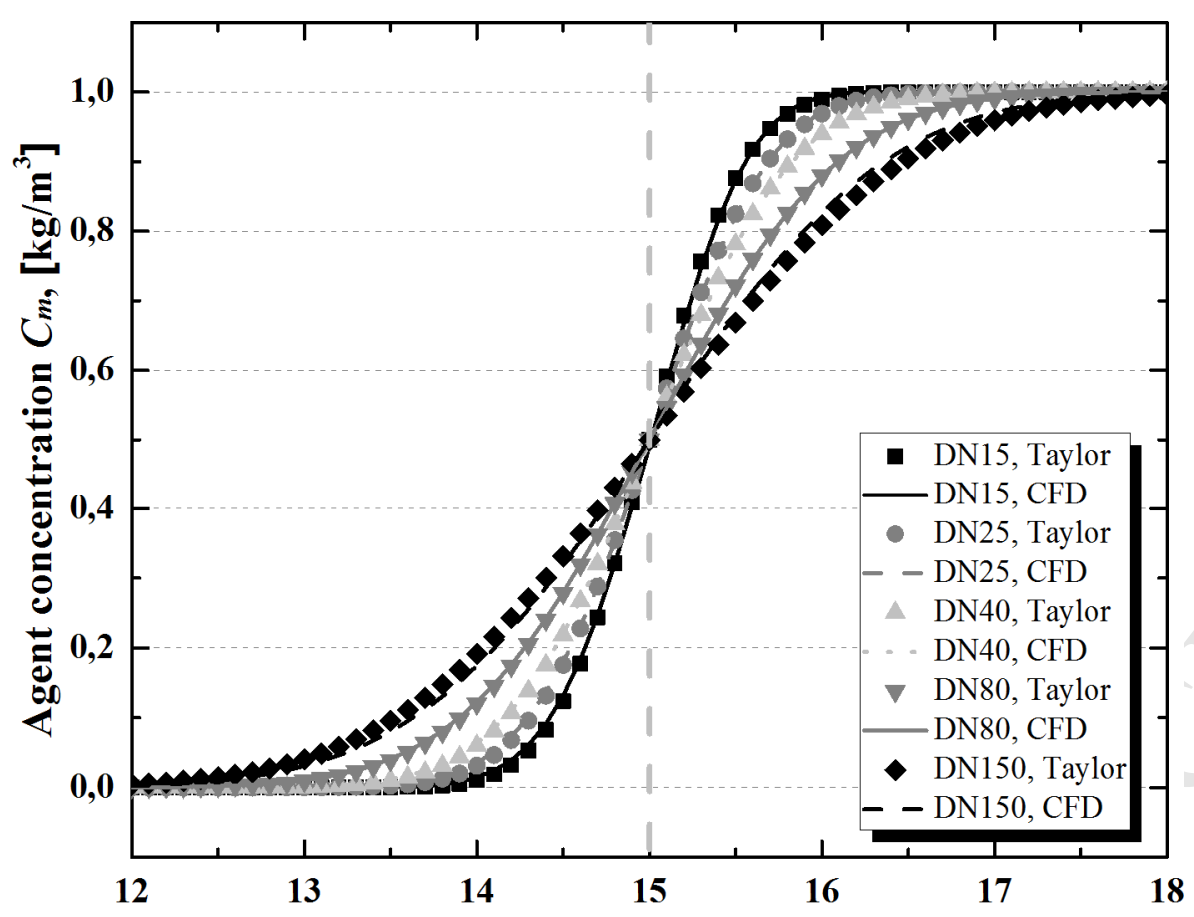

Pipe length $x,[\mathrm{~m}]$ 


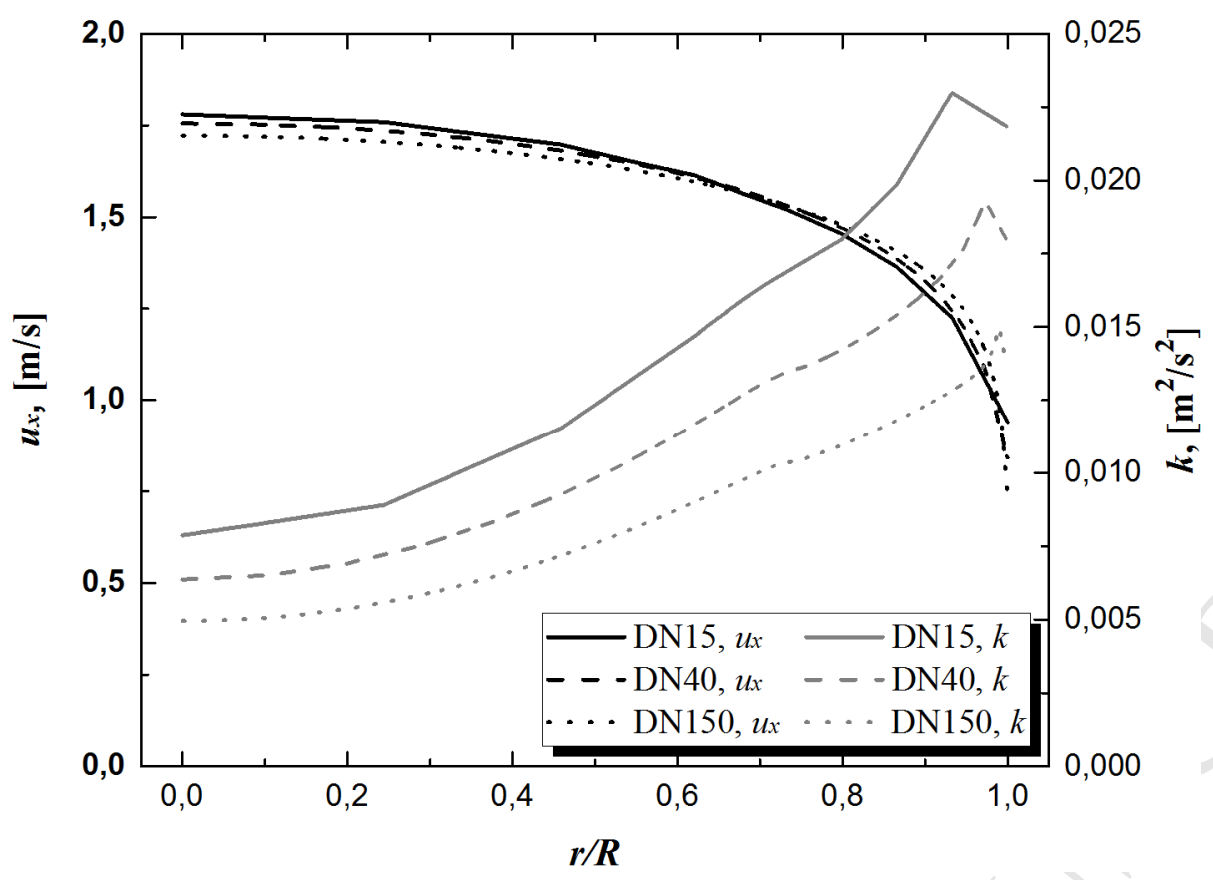




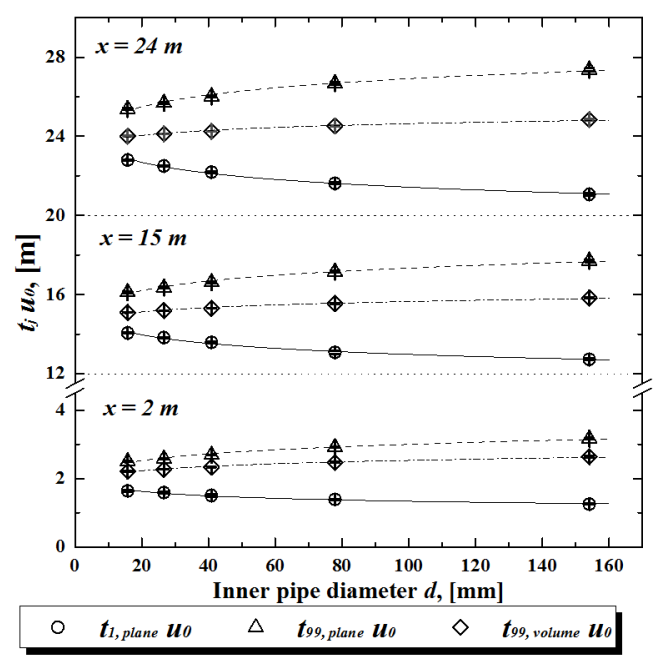




\section{ACCEPTED MANUSCRIPT}
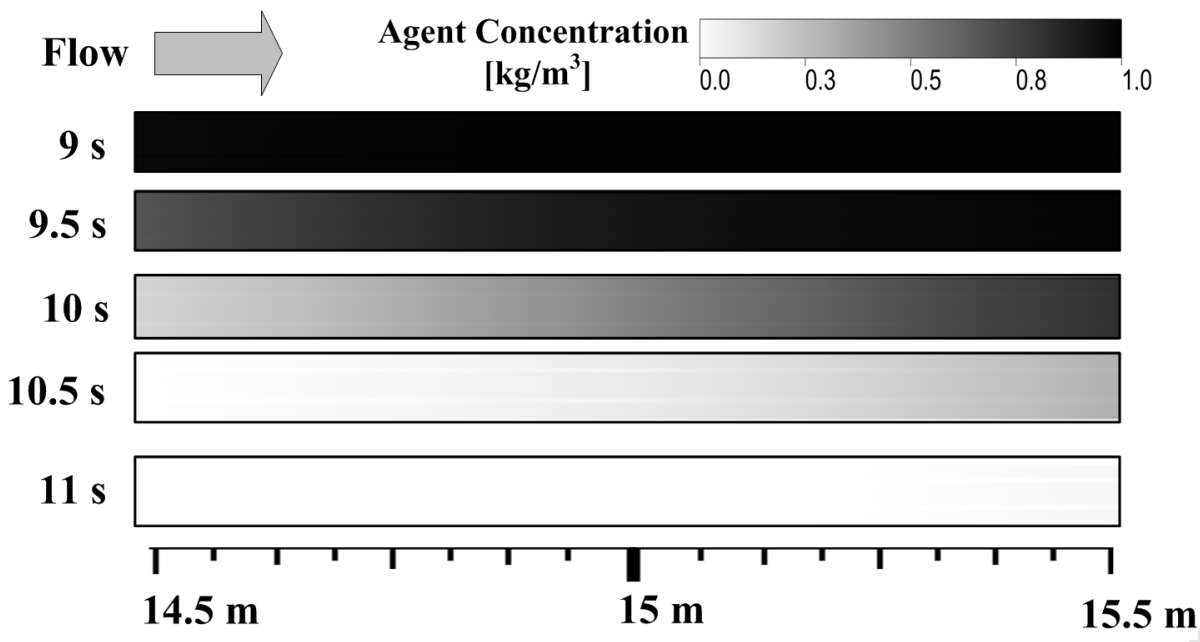


\section{Highlights}

- CFD simulates the axial mixing which occurs during the intermediate and final rinses during cleaning of straight pipes.

- The CFD results are in good agreement with the analytical models from literature.

- The model quantifies the minimum rinsing time, minimum water consumption and how to efficiently recover the cleaning agent and rinsing water.

- An algorithm and a case study show how to use the investigated knowledge to solve practical problems. 